\title{
Article \\ Exploiting of Green Synthesized Metal Oxide Nanoparticles for Spectrophotometric Determination of Levofloxacin, Cephalexin, and Cefotaxime Sodium in Commercial Products
}

\author{
Nawal Ahmed Alarfaj ${ }^{1}$, Wedad Altuhami Al-Onazi ${ }^{1}$, Amal Mohammed Al-Mohaimeed ${ }^{1}{ }^{1}$, Maha \\ Farouk El-Tohamy ${ }^{1, *(D)}$ and Hadeel Abdulaziz Alabdulmonem ${ }^{1,2}$ \\ 1 Department of Chemistry, College of Science, King Saud University, \\ P. O. Box 22452, Riyadh 11495, Saudi Arabia; nalarfaj@ksu.edu.sa (N.A.A.); walonazi@ksu.edu.sa (W.A.A.-O.); \\ muhemeed@ksu.edu.sa (A.M.A.-M.); h-chemistry@hotmail.com (H.A.A.) \\ 2 Department of Chemistry, College of Science, Princess Nourah Bint Abdulrahman University, \\ P. O. Box 84428, Riyadh 11671, Saudi Arabia \\ * Correspondence: moraby@ksu.edu.sa
}

check for updates

Citation: Alarfaj, N.A.; Al-Onazi, W.A.; Al-Mohaimeed, A.M.; El-Tohamy, M.F.; Alabdulmonem, H.A. Exploiting of Green Synthesized Metal Oxide Nanoparticles for Spectrophotometric Determination of Levofloxacin, Cephalexin, and Cefotaxime Sodium in Commercial Products. Nanomaterials 2021, 11, 1099. https://doi.org/10.3390/ nano11051099

Academic Editor:

Maurizio Muniz-Miranda

Received: 29 March 2021

Accepted: 21 April 2021

Published: 24 April 2021

Publisher's Note: MDPI stays neutral with regard to jurisdictional claims in published maps and institutional affiliations.

Copyright: () 2021 by the authors. Licensee MDPI, Basel, Switzerland. This article is an open access article distributed under the terms and conditions of the Creative Commons Attribution (CC BY) license (https:// creativecommons.org/licenses/by/ $4.0 /)$.

\begin{abstract}
In this study, two metal oxide nanoparticles $\mathrm{NiO}$ and $\mathrm{MnO}_{2}$ were synthesized from green sources Mentha spicata (M. spicata) extract and Malus domestica (M. domestica) peel extract, respectively. The optical and physical properties of the synthesized nanoparticles were characterized using spectroscopic and microscopic techniques. Simple, precise, and new spectrophotometric probes were suggested for the determination of three cephalosporin antibiotics, including levofloxacin (LVX), cephalexin (CPX), and cefotaxime sodium (CTX) in their pure form and commercial products. The spectrophotometric detection of the selected drugs is based on the catalytic enhancement of $\mathrm{NiO}$ and $\mathrm{MnO}_{2}$ nanoparticles (NPs) due to their unique optical properties. Linear relationships with main correlation coefficients 0.999 were obtained at $0.1-20,1.0-80$, and $0.001-100 \mu \mathrm{g} \mathrm{mL}^{-1}$ for the three drugs in the presence of NiONPs, whereas $0.01-60,0.1-160$, and $0.01-80 \mu \mathrm{g} \mathrm{mL}^{-1}$ were obtained in the presence of $\mathrm{MnO}_{2} \mathrm{NPs}$ at absorption wavelengths 290, 262, and $235 \mathrm{~nm}$ for LVX, CPX and CTX, respectively. The analytical methods were validated and successfully used for determination of the instigated drugs in their bulk and commercial dosage forms.
\end{abstract}

Keywords: levofloxacin; cephalexin; cefotaxime sodium; metal oxide nanoparticles; green chemistry

\section{Introduction}

Infectious diseases are one of the major human disorders that caused by various microorganisms such as bacteria, viruses, fungi, or parasites. The infection can be transferred directly or indirectly from patient to another or due to the exposure to other infected animals. The failure of treatment of the infectious diseases with medications by using unsuitable drugs or uncontrolled dose is a leading cause of death especially in young children worldwide. Untreated infectious diseases are still a serious social and medical challenge, particularly in many developing countries [1].

Nowadays, various antibiotics or antibacterial drugs are recommended to destroy or slow down the growth of Gram-positive and Gram-negative microorganisms [2]. Among these drugs are fluoroquinolones and cephalosporins. Fluoroquinolones are broad-spectrum bactericidal medications often used for genitourinary, hospital-acquired, and communityacquired infections. They are recommended as first-line therapy [3]. However, cephalosporins are a large bactericidal group of antibiotics derived from the mold Acremonium, which act by the similar pathway of penicillins [4].

The current study concerns with three different antibiotics belonging to fluoroquinolones (Levofloxacin, LVX) and cephalosporins (Cephalexin monohydrate, CPX and Cefotaxim sodium, CTX). LVX and CPX are oral active drugs used in the treatment of a variety of bacterial infections. LVX acts by inhibiting the enzymes responsible for DNA replication; 
however, CPX acts by inhibiting the cross linkage between $N$-acetyl muramic acid and $N$ acetylglucosamine in the bacterial cell wall causing cell lysis. Furthermore, CTX is a parenteral active cephalosporin antibiotic that acts by inhibiting the bacterial cell wall synthesis [5].

Several analytical methods have been reported for the determination of the investigated drugs, including spectrophotometric methods [6-8], spectrofluorometric methods [9-11], electrochemical detection such as voltammetric methods [12-14], and various chromatographic separation methods [15-17].

Although separation techniques provide a fast, automated, and accurate determination of chemical substances, they still possess many drawbacks, such as the consumption of large amounts of solvents and reagents, which are costly and require high analyst skills. Moreover, electrochemical techniques can also be carried out quickly; the outcomes are recorded as electrical signals, but unfortunately, these approaches exhibited some errors in analysis, necessitating environmental protection to lower the toxicity. However, the spectroscopic techniques, particularly spectrophotometry as a quantitative measurement technique still gained much opportunity and attention, due to its simplicity, high throughput, stability, and sensitivity [18,19].

Nanotechnology becomes one of the most prominent areas of scientific research in material science and biotechnology. Many researchers started to concentrate their vision in investigating the unique characteristics of nanomaterials and their tremendous applications [20]. With progress in all areas of industry and technology, the interest has been focused on nanoscale materials, which possess new physical and chemical properties due to the change in their size and morphology [21].

Nanomaterials are widely used in various life fields including therapeutic and biomedical applications. The main advantages of nanoparticles are increasing aqueous solubility by improving the bioavailability, increasing resistance time in the body by elevating the half-life of receptors clearance and enhance the drug targeting to specific location in the body. In addition, they reduce the required quantity of toxic drugs and enable the safe delivery of toxic therapeutic drugs with the protection of nonspecific tissues and cells from potential diverse effects [22].

Within the functional materials that can be synthesized in the nanometric scale are metal oxides, which have distinctive properties such as high electrical conductivity, excellent mechanical stability, better chemical reactivity, and enhanced catalytic activity [23].

Recently, nickel oxide $(\mathrm{NiO})$ and manganese dioxide $\left(\mathrm{MnO}_{2}\right)$ nanomaterials have gained great attention due to their excellent physical and chemical features. $\mathrm{NiO}$ is an important p-type semiconductor transition metal oxide with cubic lattice structure and large spin optical density. It has been extensively used in various applications such as electrochemical sensors [24], electronic films [25], catalysis [26], batteries [27], and biomedical applications $[28,29]$. In addition, due to the extraordinary properties of $\mathrm{MnO}_{2} \mathrm{NPs}_{\text {, they }}$ have been used in different applications including, batteries, catalysis, magnetic materials, electronic devices, and pharmaceutical analysis [30-34]. Several methods have been attempted to synthesize $\mathrm{NiO}$ and $\mathrm{MnO}_{2}$ nanoparticles, including wet chemical synthesis $[35,36]$, the sol-gel method [37,38], and thermal decomposition $[39,40]$. Interestingly, the morphology of the engineered metal oxides, e.g., shape and size, can be modulated by varying the conditions, chemicals, and concentrations used. However, the obtained nanoparticles can suffer from certain limitations such as lack of understanding the mechanism of modulation, instability, bioaccumulation, toxicity, and the need for high skill operators [41]. Therefore, the aforementioned limitations opened new and great opportunities in the research field to explore the use of green chemistry to improve the economics of chemical manufacturing and to enhance the environmental protection. The green chemistry concept presents an attractive technology to chemists, researchers, and industrialists for innovative chemistry research and applications. It is characterized as a reduction of the environmental damage accompanied by the production of materials and respective minimization and proper disposal of wastes generated during different chemical processes [42] The use of plant extracts in the biosynthesis of metal and metal oxide nanoparticles involves 
the presence of secondary metabolites as reducing agents. Commonly, biomolecules in plant extracts act as reducers, stabilizers, or both in the process of forming nanoparticles. Moreover, the same plant extract can be used to synthesize various types of nanoparticles; e.g., citrus lemon has been used for the green synthesis of silver nanoparticles and $\mathrm{ZnO}$ nanoparticles $[43,44]$.

The literature survey addressed many reports concerned with the green synthesis of nanoparticles $[45,46]$ and their prospective in various applications such as electrochemical sensors $[47,48]$, photocatalysis $[49,50]$ and pharmaceutical analysis [51,52].

This study described the use of natural sources such as Mentha spicata (M. spicata) extract and Malus domestica (M. domestica) peel extract for the synthesis of NiONPs and $\mathrm{MnO}_{2} \mathrm{NPs}$, respectively. The synthesized nanoparticles were fully characterized using various spectroscopic and microscopic techniques. In addition, the prepared metal oxide nanoparticles were employed for the spectroscopic quantification of three different antibiotics, LVX, CPX, and CTX, in their bulk powders and commercial dosage forms.

\section{Materials and Methods}

\subsection{Chemicals}

All chemicals are pure grade and used without further purification. Sigma Aldrich (Hamburg, Germany) supplied nickel nitrate hexahydrate (99.9\%), potassium permanganate $(99.0 \%)$, sodium hydroxide $(98.0 \%)$, methanol $(99.9 \%)$, ethanol $(99.9 \%)$, and acetonitrile $(99.9 \%)$. Pure grade of each of LVX, CPX, and CTX was kindly supplied by Tabuk pharmaceutical Co., Tabuk, Saudi Arabia. The pharmaceutical preparations, including Tavanic ${ }^{\circledR} 500 \mathrm{mg} \mathrm{LVX} /$ tablet (SanofiWinthrop Industries, Le Trait, France), Keflex ${ }^{\circledR} 500 \mathrm{mg}$ CPX/tablet (Facta Farmaceutical, Milano, Italy), and Foxim ${ }^{\circledR} 1 \mathrm{~g}$ CTX/5 mL vial (Tabuk pharmaceutical Co., Tabuk, Saudi Arabia) were purchased from local drug stores (Riyadh, Saudi Arabia).

\subsection{Instruments}

All spectrophotometric measurements and the characterization of the synthesized nanoparticles were carried out by measuring the UV-Vis spectra of the as-prepared nanoparticles using an Ultrospec 2100-Biochrom spectrophotometer, (Biochrom Ltd., Cambium, Cambridge, UK). However, Fourier transform infrared (FTIR) spectra of the formed nanoparticles were recorded using a PerkinElmer FTIR spectrophotometer (PerkinElmer Ltd., Yokohama, Japan). The morphology of $\mathrm{NiONPs}$ and $\mathrm{MnO}_{2} \mathrm{NPs}$ were measured by scanning electron microscope (JEM-2100F, JEOL Ltd., Tokyo, Japan) and JEM-1400 transmission electron microscope (JEOL Ltd., Akishima, Tokyo, Japan). Energy-dispersive X-ray (EDX, JSM-7610F; JEOL, Tokyo, Japan) at $20 \mathrm{kV}$ was used to determine the elemental composition of NiONPs and $\mathrm{MnO}_{2} \mathrm{NPs}$. Additionally, the XRD patterns of NiONPs and $\mathrm{MnO}_{2} \mathrm{NPs}$ were obtained by Siemens D-5000 diffractometer (Siemens, Erfurt, Germany). To control the $\mathrm{pH}$ conditions of the tested solutions, $\mathrm{pH}$-meter Metrohm model 744 (Metrohm Co., Herisau, Switzerland) was used. Distilled water (GFL, Burgwedel, Germany) was used throughout the experimental study.

\subsection{Preparation of Analytical Solutions}

\subsubsection{Preparation of Standard Solutions of LVX, CPX and CTX}

Stock solutions $\left(1000 \mu \mathrm{g} \mathrm{mL} \mathrm{m}^{-1}\right)$ of each pure LVX, CPX, and CTX were prepared separately by dissolving $0.1 \mathrm{~g}$ in $100 \mathrm{~mL}$ of distilled water. Serial dilutions were performed to prepare the working solutions in the concentration ranges of $0.1-20,1.0-80$ and $0.001-100 \mu \mathrm{g} \mathrm{mL}^{-1}$ for the analysis of LVX, CPX and CTX in the presence of NiONPs and $0.01-60,0.1-160$, and $0.01-80 \mu \mathrm{g} \mathrm{mL} \mathrm{m}^{-1}$ for the three drugs in the presence of $\mathrm{MnO}_{2} \mathrm{NPs}$, respectively. 


\subsubsection{Preparation of Tablet and Injection Samples}

Not less than ten tablets of Tavanic ${ }^{\circledR} 500 \mathrm{mg}$ LVX/tablet and Keflex ${ }^{\circledR} 500 \mathrm{mg}$ CPX/tablet were weighed and finely powdered. An accurate amount of the powder equivalent to $0.1 \mathrm{~g}$ was transferred into a 100-mL conical flask. The contents were diluted to the mark with distilled water and sonicated for $10 \mathrm{~min}$ and then filtered using Whatman filter paper No. 41. The obtained solution was further diluted to the required concentrations using distilled water and then tested as mentioned under a general procedure. For Foxime ${ }^{\circledR}$, $1 \mathrm{~g}$ of CTX/5 mL vial an equivalent volume to $1000 \mu \mathrm{g} \mathrm{mL}^{-1}$ was transferred to $100-\mathrm{mL}$ volumetric flask and diluted to the mark with distilled water. The nominal content of each drug was determined using the calibration graph or the regression equation.

\subsection{Preparation of M. spicata and M. domestica Extracts}

M. spicata leaves and $M$. domestica peels were perfectly rinsed with distilled water and oven dried at $70{ }^{\circ} \mathrm{C}$. The obtained biomass was ground into fine powder and kept at ambient temperature. The M. spicata extract was prepared by mixing $10 \mathrm{~g}$ of dried $M$. spicata biomass in $100 \mathrm{~mL}$ of distilled water boiled under constant stirring for $10 \mathrm{~min}$. The content was cooled and filtered using Whatman No. 1 with pore size $25 \mu \mathrm{m}$ filter paper. The resulted extract was stored in a refrigerator at $4{ }^{\circ} \mathrm{C}$ for further uses.

The $M$. domestica peel extract was prepared by mixing $10 \mathrm{~g}$ of $M$. domestica peels biomass in $100 \mathrm{~mL}$ of distilled water and refluxed for $1 \mathrm{~h}$ at $70{ }^{\circ} \mathrm{C}$. Cotton fabric was used to remove the solid particles from the formed suspension. The suspension was centrifuged for $10 \mathrm{~min}$ at 10,000 rpm and filtered using $0.2 \mu \mathrm{m}$ filter (Millipore, Bedford, TX, USA), and the $\mathrm{pH}$ of the extract ranged between 3.7 and 4 . The resulted extract was stored in a refrigerator at $4{ }^{\circ} \mathrm{C}$ for further use. Since the obtained aqueous extracts have various secondary metabolites containing hydroxyl and carbonyl groups, these functional groups allowed the plant extracts to serve as reducing and stabilizing agents for the green synthesis of NiONPs and $\mathrm{MnO}_{2} \mathrm{NPs}$, respectively [53].

\subsection{Green Synthesis of NiONPs and $\mathrm{MnO}_{2} \mathrm{NPs}$}

The $\mathrm{NiO}$ and $\mathrm{MnO}_{2}$ nanoparticles were synthesized using $M$. spicata and $M$. domestica peels extract, respectively. The synthesis of NiONPs was carried out under constant stirring by reducing $100 \mathrm{~mL}$ of nickel nitrate hexahydrate $\left(0.1 \mathrm{~mol} \mathrm{~L}^{-1}\right)$ using $50 \mathrm{~mL}$ of M. spicat extract as a reducing agent. Subsequently, $5 \mathrm{~mL}$ of sodium hydroxide solution $\left(0.1 \mathrm{~mol} \mathrm{~L}^{-1}\right)$ was added dropwise. The mixture was kept under magnetic stirring for $4 \mathrm{~h}$ at room temperature until the formation of NiONPs. The obtained nanoparticles were filtered using Whatman filter paper No. 41 and then washed with distilled water three times to remove any excess of sodium hydroxide. The obtained NiONPs were dried at $100{ }^{\circ} \mathrm{C}$ for $12 \mathrm{~h}$ and calcined at $350{ }^{\circ} \mathrm{C}$ for $3 \mathrm{~h}$.

$\mathrm{MnO}_{2}$ nanoparticles were synthesized by adding $50 \mathrm{~mL}$ of (M. domestica) peels extract to $100 \mathrm{~mL}$ of potassium permanganate solution $\left(0.1 \mathrm{~mol} \mathrm{~L}^{-1}\right)$. Approximately $5 \mathrm{~mL}$ of $1.0 \mathrm{~mol} \mathrm{~L}^{-1}$ sodium hydroxide was added dropwise until the $\mathrm{pH}$ elevated to 8 . The formed dark brown precipitate was filtered using Whatman filter paper No. 41, washed with distilled water, and calcined at $700{ }^{\circ} \mathrm{C}$ for $3 \mathrm{~h}$.

The NiONPs and $\mathrm{MnO}_{2} \mathrm{NPs}$ stock solutions were prepared by adding $0.1 \mathrm{~g}$ of each nanopowder to $100 \mathrm{~mL}$ distilled water. The suspensions were sonicated for $10 \mathrm{~min}$ and stored in refrigerator at $4{ }^{\circ} \mathrm{C}$. The suitable volumes of added nanoparticles were selected for further investigations by testing different volumes of the previously prepared nanoparticles $(0.1 \mathrm{~g} / 100 \mathrm{~mL})$ in the ranges of $0.1-1.4 \mathrm{~mL}$ and $0.5-3.0 \mathrm{~mL}$ of NiONPs and $\mathrm{MnO}_{2} \mathrm{NPs}$, respectively. It was found that the highest absorption maxima were achieved by adding $0.2,0.6$, and $0.4 \mathrm{~mL}$ of NiONPs and 2.0, 1.0, and $1.5 \mathrm{~mL}$ of $\mathrm{MnO}_{2} \mathrm{NPs}$. Thus, these volumes were selected for further experimental analysis. 


\subsection{General Analytical Procedure}

General Analytical Procedure Using NiONPs and $\mathrm{MnO}_{2} \mathrm{NPs}$

Aliquots of solutions with different concentrations of LVX $\left(0.001-60 \mu \mathrm{g} \mathrm{mL}^{-1}\right), \mathrm{CPX}(1-$ $\left.80 \mu \mathrm{g} \mathrm{mL}^{-1}\right)$, and CTX $\left(0.001-100 \mu \mathrm{g} \mathrm{mL}^{-1}\right)$ were transferred into a series of $10 \mathrm{~mL}$ volumetric flasks. Then, $0.2,0.6$, and $0.4 \mathrm{~mL}$ of NiONPs was added to LVX, CPX, and CTX, respectively. However, aliquot solutions of $\operatorname{LVX}\left(0.01-100 \mu \mathrm{g} \mathrm{mL}^{-1}\right), \mathrm{CPX}\left(0.01-160 \mu \mathrm{g} \mathrm{mL}^{-1}\right)$, and CTX $\left(0.01-120 \mu \mathrm{g} \mathrm{mL}^{-1}\right)$ were transferred into a series of $10 \mathrm{~mL}$ volumetric flasks and 2.0, 1.0, and $1.5 \mathrm{~mL}$ of $\mathrm{MnO}_{2} \mathrm{NPs}$ were added to LVX, CPX, and CTX, respectively. The absorbance of the solutions was measured at 290, 262, and $235 \mathrm{~nm}$, respectively.

\section{Results}

\subsection{Characterization of NiONPS and $\mathrm{MnO}_{2} \mathrm{NPS}_{\mathrm{S}}$}

Various spectroscopic and microscopic techniques were used to characterize the formation of NiONPs and $\mathrm{MnO}_{2} \mathrm{NPs}$. The optical features of each synthesized metal oxide nanoparticles were studied using UV-Vis spectroscopy. The absorption spectra in Figure 1a showed two broad absorption peaks at 302 and $392 \mathrm{~nm}$ for the $\mathrm{Ni}\left(\mathrm{NO}_{3}\right)_{2}$ precursor and one absorption peak at $289 \mathrm{~nm}$ for $M$. spicata leaves extract. However, NiONPs displayed a significant absorption peak at $320 \mathrm{~nm}$ due to the unique property of surface plasmon resonance (SPR). The obtained results were in agreement with the literature [54]. In Figure $1 \mathrm{~b}$, the absorption spectra displayed a significant absorption peak at $550 \mathrm{~nm}$ related to potassium permanganate precursor, while another peak can be observed at $280 \mathrm{~nm}$, which is corresponding to $M$. domestica extract, and the appeared peak at $350 \mathrm{~nm}$ was assigned to be corresponding to $\mathrm{MnO}_{2} \mathrm{NPs}$. The obtained results matched those in the literature [55].
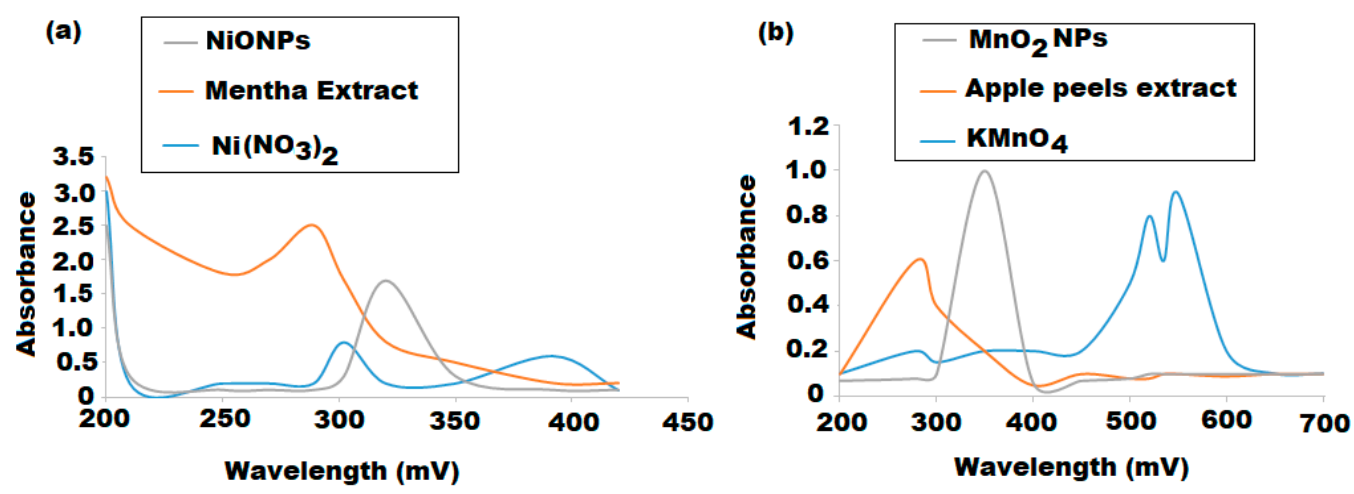

Figure 1. UV-Vis absorption spectra of synthesized (a) NiONPs and (b) $\mathrm{MnO}_{2} \mathrm{NPs}$ using Mentha spicata leaves and Malus domestica peel extracts, respectively.

The band gap energy of the as-prepared NiONPs and $\mathrm{MnO}_{2} \mathrm{NPs}_{\mathrm{s}}$ was calculated from the formula $\mathrm{E}_{\mathrm{g}}=\mathrm{h} v$ where, $\mathrm{E}_{\mathrm{g}}$ is the band gap energy, $\mathrm{h}$ is a blank constant, and $v$ is the frequency. The band gaps of NiONPs and $\mathrm{MnO}_{2} \mathrm{NPs}$ were calculated as 3.56 and $3.62 \mathrm{eV}$, respectively. The red shift of absorption spectrum to 320 and $350 \mathrm{~nm}$ for NiONPs and $\mathrm{MnO}_{2} \mathrm{NPs}$, respectively and the decrease of band gap values revealed the formation of nanoscale materials. According to the literature [54,55], these distinct peaks represent the formation of NiONPs and $\mathrm{MnO}_{2} \mathrm{NPs}$ with particle sizes of approximately 50-100 nm, respectively. Additionally, in nanoscale materials, the relation between the band gap and the size diameter of particle is inversely proportional to each other. The higher the nanoparticles in size diameter, the lower in band gap value, due to quantization effect, but it never reaches zero [56].

To ascertain the purity and nature of NiONPs surface, FTIR spectrum was recorded. As shown in Figure 2a, the broad absorption band at $645.65 \mathrm{~cm}^{-1}$ is assigned to $\mathrm{Ni}-\mathrm{O}$ stretching vibration mode, and the broadness of the absorption band indicates that the $\mathrm{NiO}$ powder is a nanocrystal [57]. The presence of a broad band at $3436.08 \mathrm{~cm}^{-1}$ was attributed 
to $\mathrm{O}-\mathrm{H}$ stretching vibration [58]. The weak band near $1624.64 \mathrm{~cm}^{-1}$ is assigned to $\mathrm{H}-\mathrm{O}-\mathrm{H}$ bending vibration mode, due to the adsorption of atmospheric moisture in air [59].
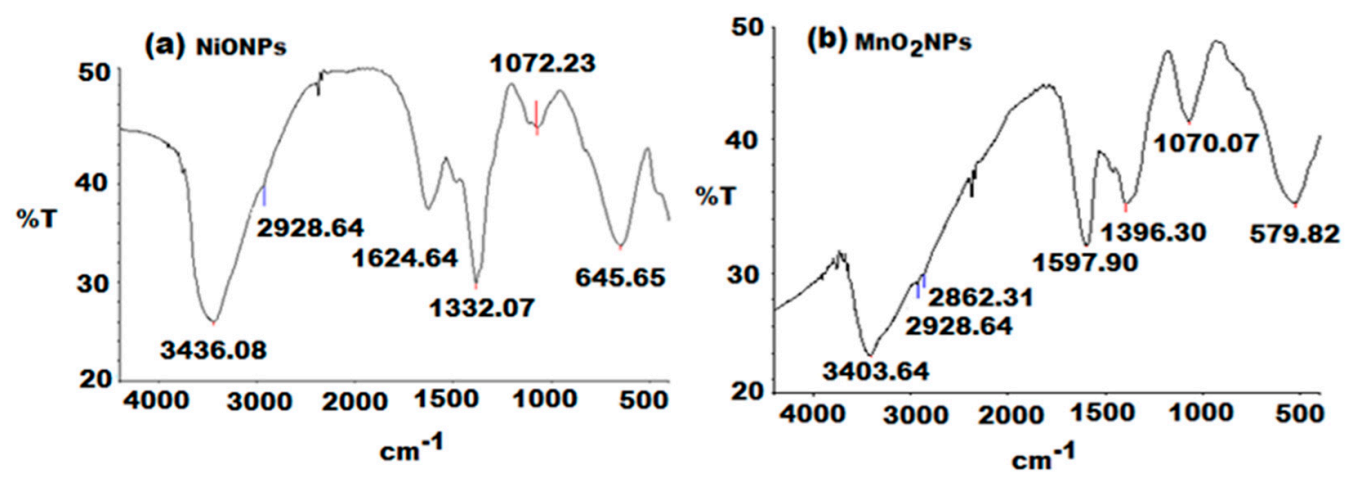

Figure 2. FTIR spectra in the range of $4000-500 \mathrm{~cm}^{-1}$ of green synthesized (a) NiONPs and (b) $\mathrm{MnO}_{2} \mathrm{NPs}$ using Mentha spicata and Malus domestica peel extract, respectively.

Another vibrational band that was observed at 1332.07 and $1072.23 \mathrm{~cm}^{-1}$ may be attributed to the carbonyl group $\mathrm{C}=\mathrm{O}$ stretching vibration band. The serrated absorption bands in the region $1000-1500 \mathrm{~cm}^{-1}$ are assigned to the $\mathrm{O}-\mathrm{C}=\mathrm{O}$ symmetric and asymmetric stretching vibrations and the $\mathrm{C}-\mathrm{O}$ stretching vibration [60], which indicated that the ultrafine powders tend to have strong physical absorption to $\mathrm{H}_{2} \mathrm{O}$ and $\mathrm{CO}_{2}$. The result of this FTIR spectroscopic study confirmed the reduction of nickel nitrate into NiONPs by using mint extract as reducing agent in the presence of $\mathrm{NaOH}$. FTIR spectroscopy was also used to study the chemical composition of the $\mathrm{MnO}_{2} \mathrm{NPs}$ surface (Figure 2b).

The absorption band located at $579.82 \mathrm{~cm}^{-1}$ was ascribed to the typical collision $\mathrm{O}-\mathrm{Mn}-\mathrm{O}$ vibrations of the prepared $\mathrm{MnO}_{2}$ [61]. The recorded spectra revealed a broad band at $3403.64 \mathrm{~cm}^{-1}$ for $\mathrm{O}-\mathrm{H}$ symmetric stretching frequency vibration and two bands at 2928.64 and $2862.31 \mathrm{~cm}^{-1}$ for $\mathrm{C}-\mathrm{H}$ vibration stretching vibration bands [62]. Additionally, the bands at 1597.40 and $1396.30 \mathrm{~cm}^{-1}$ were corresponding to the existence of aromatic unsaturated $C=C$. Furthermore, the spectrum showed an absorption band at $1070.07 \mathrm{~cm}^{-1}$ due to the presence of $\mathrm{C}-\mathrm{O}$ stretching vibration [62].

The particle size distributions of NiONPs and $\mathrm{MnO}_{2} \mathrm{NPs}$ were determined by a particle size analyzer (PSA). The obtained results showed that the particle size distributions were around $100 \mathrm{~nm}$ for both NiONPs and $\mathrm{MnO}_{2} \mathrm{NPs}$, respectively (Figure 3a,b). The obtained results confirmed that the synthesized $\mathrm{NiO}$ and $\mathrm{MnO}_{2}$ using $M$. spicata leaf and $M$. domestica peel extracts are in nanoparticles form.
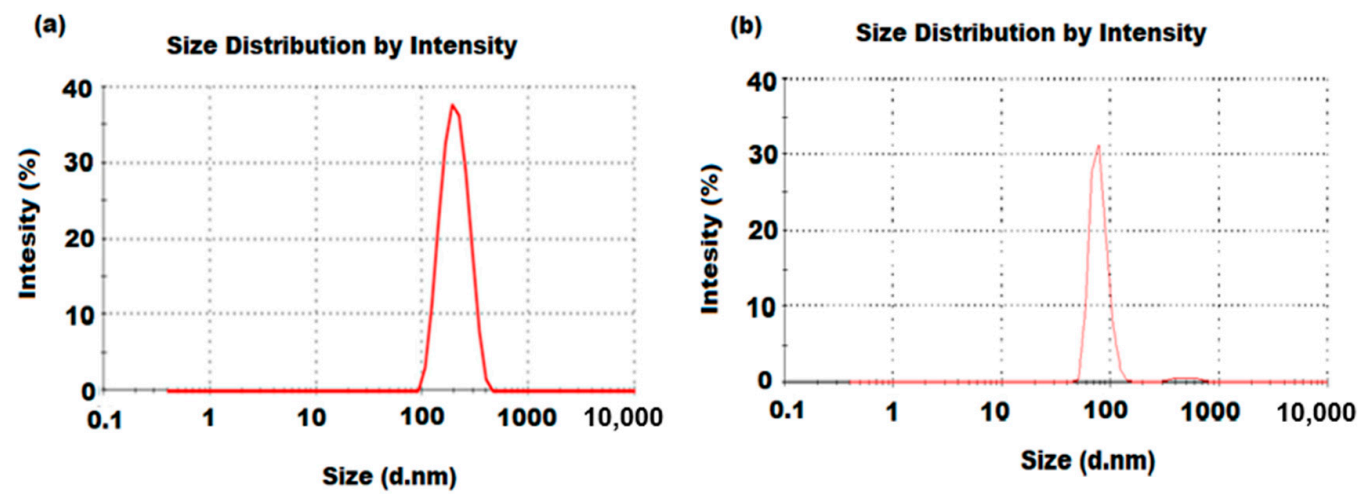

Figure 3. Particle size distribution of (a) NiONPs and (b) $\mathrm{MnO}_{2} \mathrm{NPs}$ synthesized by Mentha spicata and Malus domestica peel extract, respectively.

X-ray diffraction patterns of NiONPs and $\mathrm{MnO}_{2} \mathrm{NPs}$ were recorded over a $2 \theta$ range of $20-80^{\circ}$ to investigate the crystal structure of the as-prepared metal oxide nanoparticles. 
The phase purity of the $\mathrm{NiO}$ nanoparticles sample was studied using XRD analysis. The XRD pattern (Figure $4 \mathrm{a}$ ) showed five different peaks at $(2 \theta)$ of $34.17^{\circ}, 42.26^{\circ}, 62.73^{\circ}, 75.29^{\circ}$, and $79.16^{\circ}$ corresponding to (1 11 1), (2 0 0), (2 20 ), (3 11 1), and (2 2 2) planes, respectively. All these XRD peaks can be excellently indexed to the face-centered cubic crystalline shape of $\mathrm{NiO}$, which are matched with that of the standard spectrum (JCPDS card number 04-0835) [63]. Debye-Scherrer formula was followed to calculate the grain size of the crystallites of NiONPs.

$$
\mathrm{D}=0.9 \lambda / \beta \operatorname{Cos} \theta
$$

where $D$ is the crystal size, $\lambda=0.15418 \mathrm{~nm}$ is the wavelength used in the present study, and $\beta$ is the Bragg angle $\theta$ of the $X$-ray diffraction peak. The average crystallite size of the as-synthesized nanoparticles was $88.63 \mathrm{~nm}$.

(a)

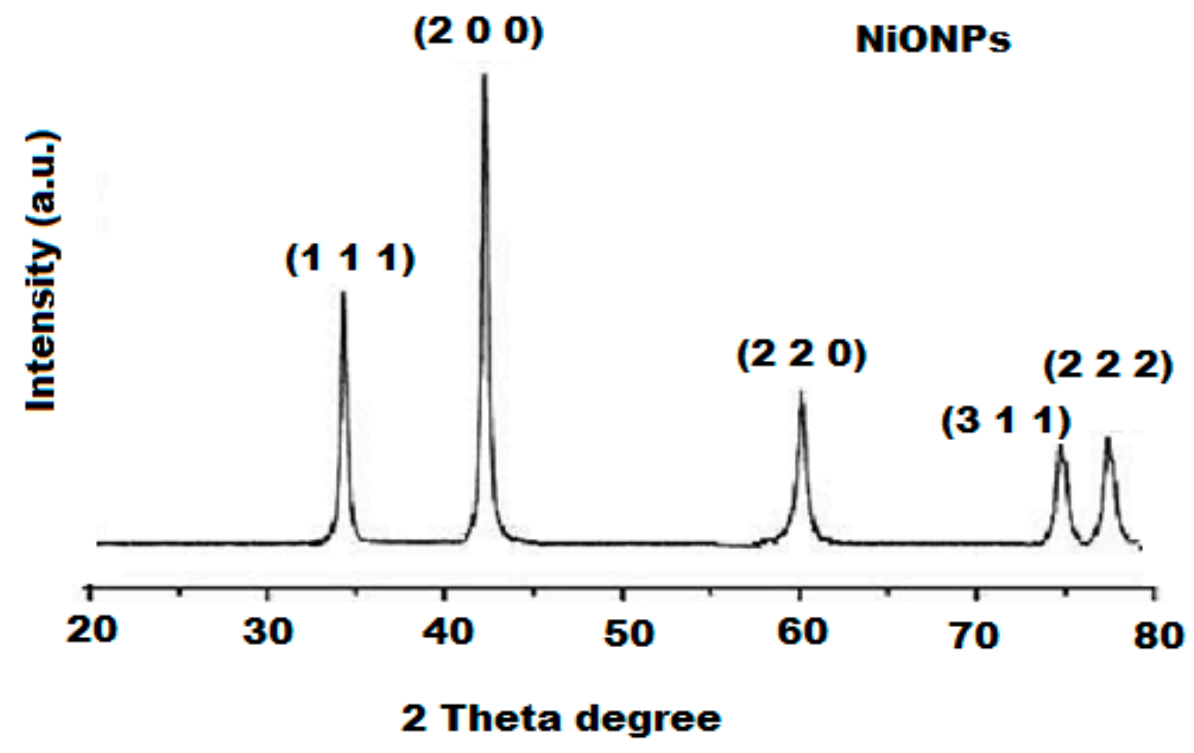

(b)

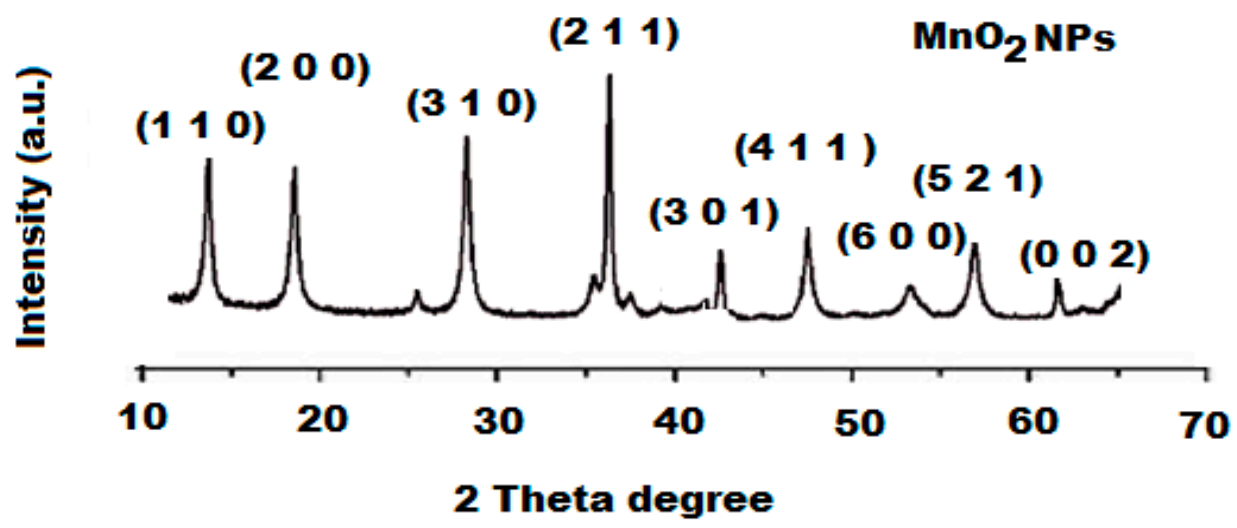

Figure 4. XRD spectra of the green synthesized (a) NiONPs and (b) $\mathrm{MnO}_{2} \mathrm{NPs}$ using Mentha spicata and Malus domestica peel extract, respectively.

The XRD pattern of $\mathrm{MnO}_{2}$ nanoparticles (Figure $4 \mathrm{~b}$ ) displayed diffraction peaks at $2 \theta$ degree angles of $13.8^{\circ}, 17.92^{\circ}, 29.52^{\circ}, 38.12^{\circ}, 43.70^{\circ}, 50.69^{\circ}, 54.91^{\circ}, 56.54^{\circ}$, and $62.15^{\circ}$ corresponding to (1 00 0), (2 $\left.\begin{array}{lll}2 & 0\end{array}\right),\left(\begin{array}{lll}3 & 1 & 0\end{array}\right),\left(\begin{array}{lll}2 & 1 & 1\end{array}\right),\left(\begin{array}{lll}3 & 0 & 1\end{array}\right),\left(\begin{array}{lll}4 & 1 & 1\end{array}\right),\left(\begin{array}{lll}6 & 0 & 0\end{array}\right),\left(\begin{array}{lll}5 & 2 & 1\end{array}\right)$, and $\left(\begin{array}{lll}0 & 0 & 2\end{array}\right)$ tetragonal structure. The recorded peaks are in good agreement with the JCPDS Card number of 44-0141 [64]. Debye-Scherrer formula was followed to calculate the particle size of the crystallites of $\mathrm{MnO}_{2} \mathrm{NPs}$. The average crystallite size of the as-synthesized nanoparticles was $85.66 \mathrm{~nm}$. 
EDX analysis was used to quantify the chemical compositions of the green synthesized $\mathrm{NiONPs}$ and $\mathrm{MnO}_{2} \mathrm{NPs}$ using $M$. spicata and $M$. domestica extracts, respectively (Figure 5a,c). The results indicated that in NiONPs, the weight percentage of $\mathrm{Ni}$ and $\mathrm{O}$ were $76.06 \%$ and $23.94 \%$, respectively. The atomic percentage was found to be $\mathrm{Ni}(46.40 \%)$ and $\mathrm{O}(53.60 \%)$. However, in case of $\mathrm{MnO}_{2} \mathrm{NP}$, the weight percentage of $\mathrm{Mn}$ and $\mathrm{O}$ are $61.31 \%$ and $38.69 \%$, respectively. The atomic percentage was found to be $\mathrm{Mn}(31.57 \%)$ and $\mathrm{O}(68.43 \%)$. No additional peaks corresponding to other elements were observed, revealing the purity of the synthesized NiONPs and $\mathrm{MnO}_{2} \mathrm{NPs}$ (Figure $5 \mathrm{~b}, \mathrm{~d}$ ).

(a)

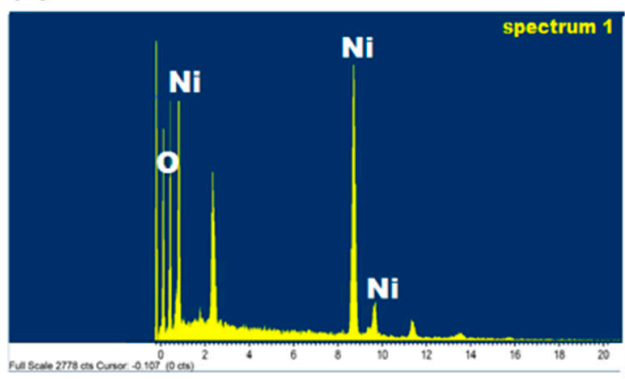

(c)



(b)

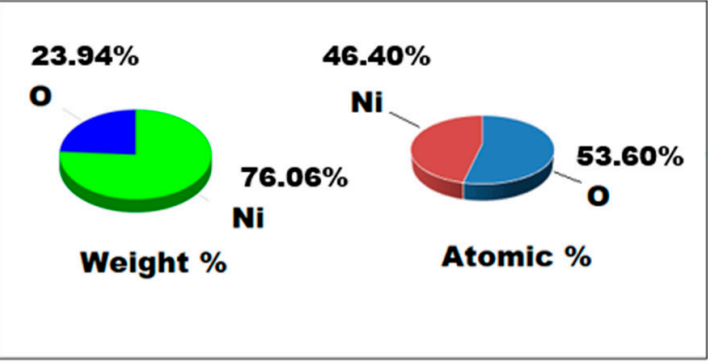

(d)

Figure 5. (a,c) EDX spectra of the green synthesized NiONPs and $\mathrm{MnO}_{2} \mathrm{NPs}$ using Mentha spicata and Malus domestica peel extracts, $(\mathbf{b}, \mathbf{d})$ represent the weight percentage and atomic percentage of the synthesized nanoparticles, respectively.

The TEM images of the NiONPs (Figure 6a) indicated that the prepared metal oxide nanoparticles are fairly uniformly distributed, spherical in shape, and their sizes are between 50 and $100 \mathrm{~nm}$. TEM images of $\mathrm{MnO}_{2} \mathrm{NPs}$ synthesized with the $M$. domestica extract showed the presence of short and long rods that are dense and agglomerated with particle size around 80-100 nm (Figure 6b).

Additionally, the surface morphology of NiONPs and $\mathrm{MnO}_{2} \mathrm{NPs}$ was investigated under SEM using 30,000 $\times$ magnification. The image in (Figure 6c) showed the morphological structure of NiONPs, which appeared to be spherical and aggregated particles with particles size around $100 \mathrm{~nm}$. The image in (Figure 6d) indicated that the $\mathrm{MnO}_{2} \mathrm{NPs}_{\text {are }}$ nanorodes in the range $80-100 \mathrm{~nm}$ with significant aggregation that appeared to have a caddice clew morphology $[65,66]$.

\subsection{Optimum Experimental Conditions}

Various experimental parameters were optimized, including the influence of the solvents, volume of nanoparticles, response time, and temperature. The conditions were optimized by varying one variable and observing its effect on the absorbance maxims of samples. 


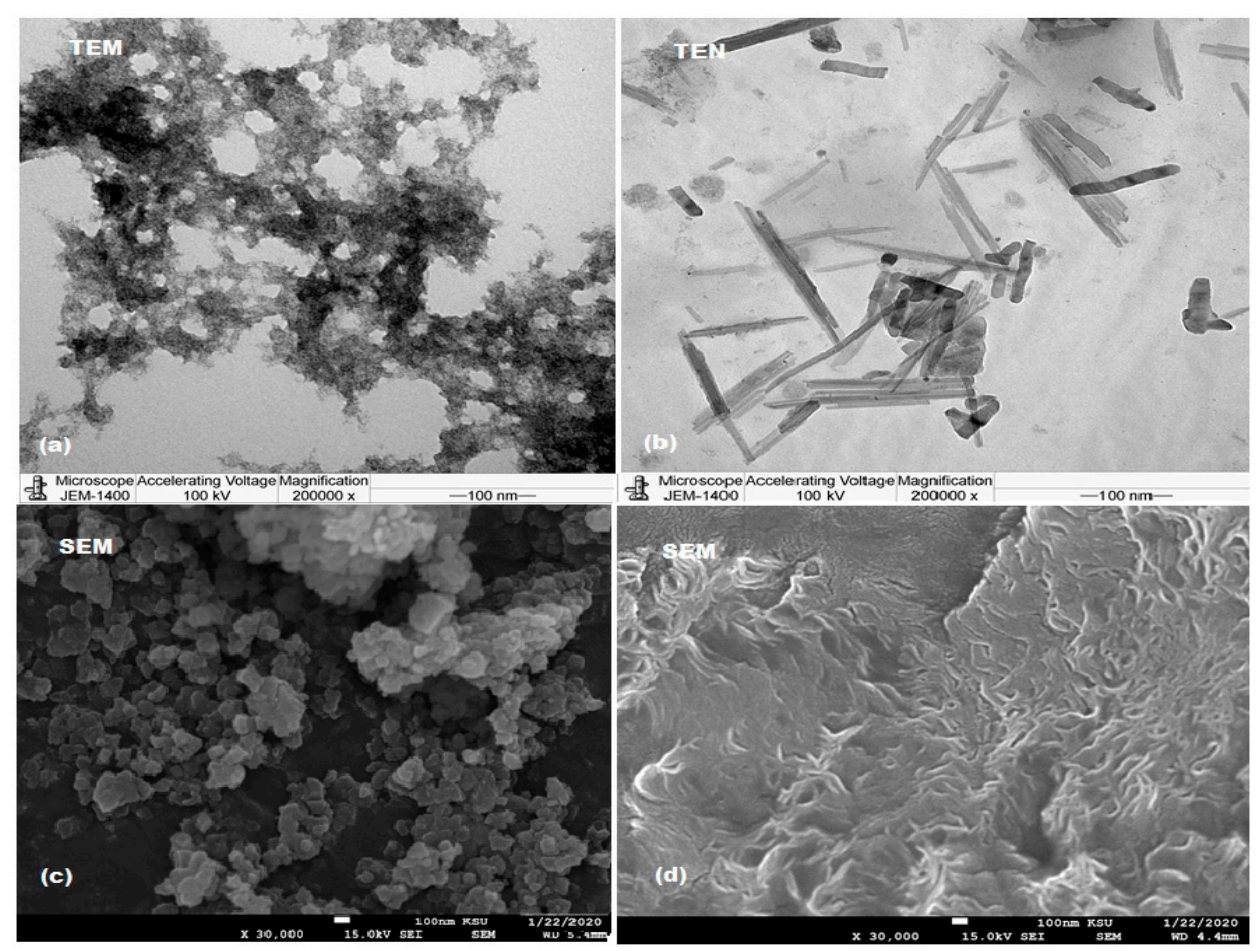

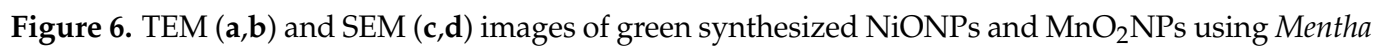
spicata and Malus domestica peel extracts, respectively.

\subsubsection{Effect of Solvents on the Absorption Spectra}

The UV-Vis absorption spectra of $10 \mu \mathrm{gL}^{-1}$ of each LVX, CPX, and CTX solution in the presence of different solvents such as water, methanol, ethanol, and acetonitrile were studied. The absorption maxima were recorded according to the solvent nature. Figure 7a showed the absorbance obtained at 290, 262, and $235 \mathrm{~nm}$, respectively, of the three investigated drugs dissolved in different solvents, in the absence of nanoparticles.
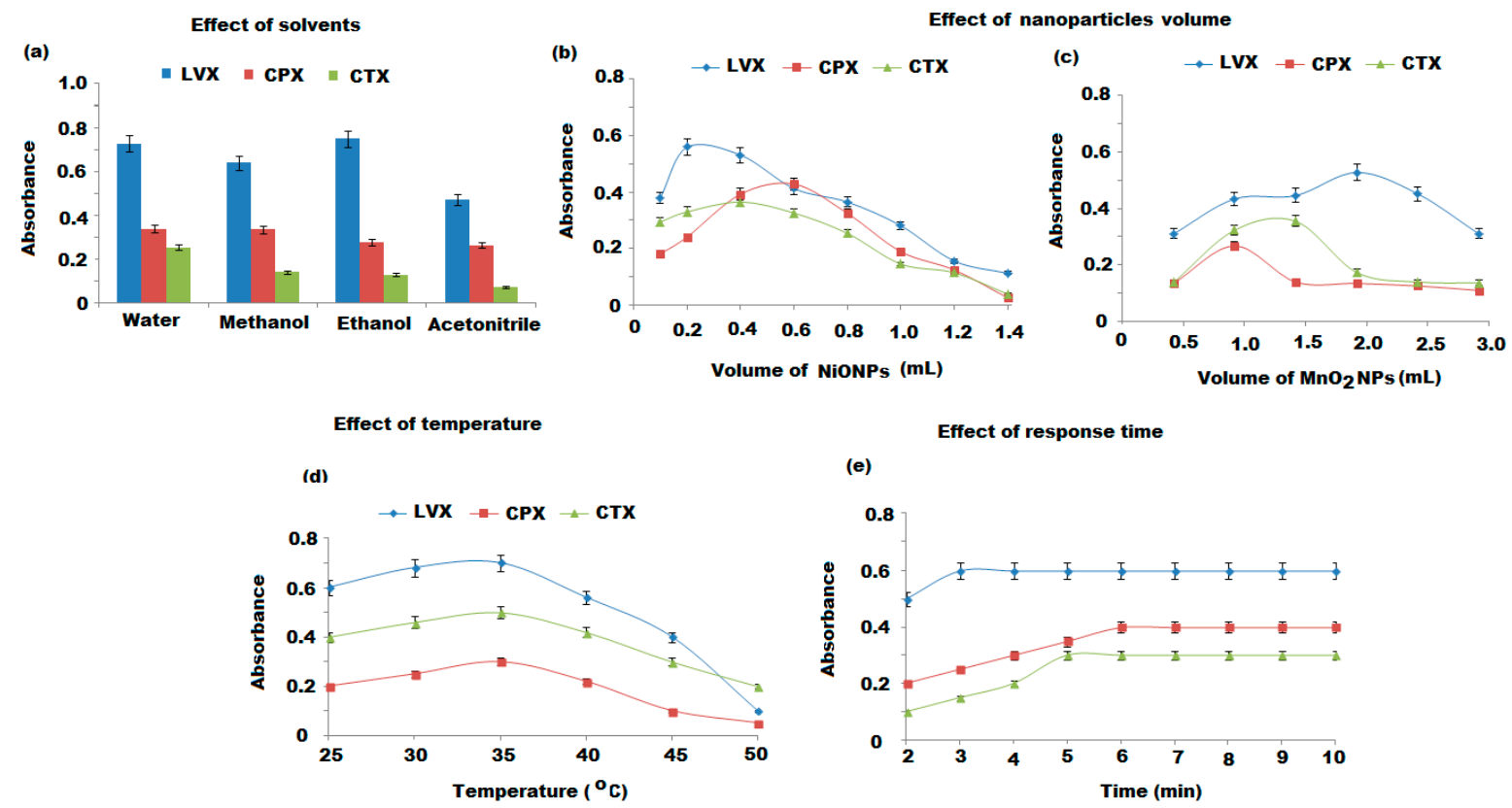

Figure 7. (a) Effect of solvents on the absorbance maxima of the three investigated drugs dissolved in different solvents and in the absence of nanoparticles, $(\mathbf{b}, \mathbf{c})$ effect of NiONPs and $\mathrm{MnO}_{2} \mathrm{NPs}$ volume, (d,e) effect of temperature $25-50{ }^{\circ} \mathrm{C}$ and effect of response time $2-10 \mathrm{~min}$ on the absorption of $10 \mu \mathrm{g} \mathrm{mL} \mathrm{m}^{-1}$ of LVX, CPX, and CTX solutions in the presence of the corresponding nanoparticles as indicated previously. 


\subsubsection{Volume of NiONPs and $\mathrm{MnO}_{2} \mathrm{NPs}$}

The effect of the volume of the as-prepared NiONPs and $\mathrm{MnO}_{2} \mathrm{NPs}$ in the ranges of (0.1-1.4 mL) and (0.5-3.0 mL) was investigated using $10 \mu \mathrm{g} \mathrm{mL}-1$ of each LVX, CPX, and CTX solutions. The maximum absorption peaks were recorded after adding $0.2,0.6$, and $0.4 \mathrm{~mL}$ of NiONPs to LVX, CPX, and CTX, respectively, or by adding 2.0, 1.0, and $1.5 \mathrm{~mL}$ of $\mathrm{MnO}_{2} \mathrm{NPs}$ to the above-mentioned drugs, respectively. Thus, these volumes were used for further experimental studies (Figure $7 \mathrm{~b}, \mathrm{c}$ ).

\subsubsection{Effect of Temperature and Response Time}

The effect of temperature on the spectrophotometric determination of LVX, CPX, and CTX was studied by elevating the temperature of the tested samples and blank from 25 to $50{ }^{\circ} \mathrm{C}$ using water baths. It was observed that the absorbance of the three drugs was decreased by increasing the temperature more than $25-35^{\circ} \mathrm{C}$. Therefore, the suggested spectrophotometric method for the determination of the investigated drugs was performed at ambient temperature (Figure 7d). Further study was performed at various time intervals 2-10 min to evaluate the effect of response time between each drug sample and the added nanoparticles. The absorbance of each drug was recorded at 290, 262, and $235 \mathrm{~nm}$ for LVX, CPX, and CTX, respectively. Fast responses were noticed within 3, 6, and $5 \mathrm{~min}$ for the tested drugs in the presence of NiONPs and $\mathrm{MnO}_{2} \mathrm{NPs}$, respectively. The optimized conditions for the suggested spectrophotometric method were presented in Table 1.

Table 1. Optimized conditions for the determination of LVX, CPX, and CTX using the proposed spectrophotometric method in the presence of NiONPs and $\mathrm{MnO}_{2} \mathrm{NPs}$, respectively.

\begin{tabular}{cccc}
\hline Parameters & LVX & CPX & CTX \\
\hline Wavelength $(\mathrm{nm})$ & 290 & 262 & 235 \\
\hline Volume of added nanoparticles & & & \\
NiONPs & $0.2 \mathrm{~mL}$ & $0.6 \mathrm{~mL}$ & $0.4 \mathrm{~mL}$ \\
$\mathrm{MnO}_{2} \mathrm{NPs}$ & $2.0 \mathrm{~mL}$ & $1.0 \mathrm{~mL}$ & $1.5 \mathrm{~mL}$ \\
\hline Temperature ${ }^{\circ} \mathrm{C}$ & 25 & 25 & 25 \\
\hline Response Time $(\mathrm{min})$ & 3 & 6 & 5 \\
\hline
\end{tabular}

\subsection{Absorption Spectra}

The proposed spectrophotometric method based on the optical properties of the green synthesized metal oxide nanoparticles (NiONPs and $\mathrm{MnO}_{2} \mathrm{NPs}$ ) was applied to determine LVX, CPX, and CTX. After 3, 6, and $5 \mathrm{~min}$ response time for $10 \mu \mathrm{g} \mathrm{mL}^{-1}$ of each drug with $0.2,0.6$, and $0.4 \mathrm{~mL}$ of NiONPs and 2.0, 1.0, and $1.5 \mathrm{~mL}$ of $\mathrm{MnO}_{2} \mathrm{NPs}$, the absorbance was recorded at wavelengths 290, 262, and $235 \mathrm{~nm}$, respectively. As shown in Figure 8a-f, the absorption spectra were significantly increased by 2 -fold compared to the native spectra of the selected drugs. The spectrophotometric analysis could be suitable for the quantification of the tested drugs.

\subsection{Method Validation}

The developed methods for the determination of the studied drugs were validated, and the data were reported with respect to ICH guidelines [67].

The linear relationships of the investigated drugs in the presence of NiONPs and $\mathrm{MnO}_{2} \mathrm{NPs}$ were determined by plotting the absorption vs. LVX, CPX, and CTX concentrations. The investigated drugs displayed linearity over the concentration ranges $0.1-20$, 1.0-80, and $0.001-100 \mu \mathrm{g} \mathrm{mL}^{-1}$ for LVX, CPX, and CTX in the presence of NiONPs, whereas $0.01-60,0.1-160$, and $0.01-80 \mu \mathrm{g} \mathrm{mL}{ }^{-1}$ were obtained in the presence of $\mathrm{MnO}_{2} \mathrm{NPs}$ (Table 2). The least square regression equations were derived as $\mathrm{Y}=0.0492 \mathrm{C}+0.0334(\mathrm{r}=0.9986)$, $\mathrm{Y}=0.0319 \mathrm{C}+0.0699(\mathrm{r}=0.9999)$, and $\mathrm{Y}=0.0304 \mathrm{C}+0.0312(\mathrm{r}=0.9995)$ for LVX, CPX, and CTX in the presence of NiONPs and $Y=0.0464 C+0.0956,(r=0.9974) Y=0.0163 C+0.0489$ 
$(r=0.9995)$, and $\mathrm{Y}=0.0321 \mathrm{C}+0.0835(\mathrm{r}=0.9998)$ for the above-mentioned drugs in the presence of $\mathrm{MnO}_{2} \mathrm{NPs}$.
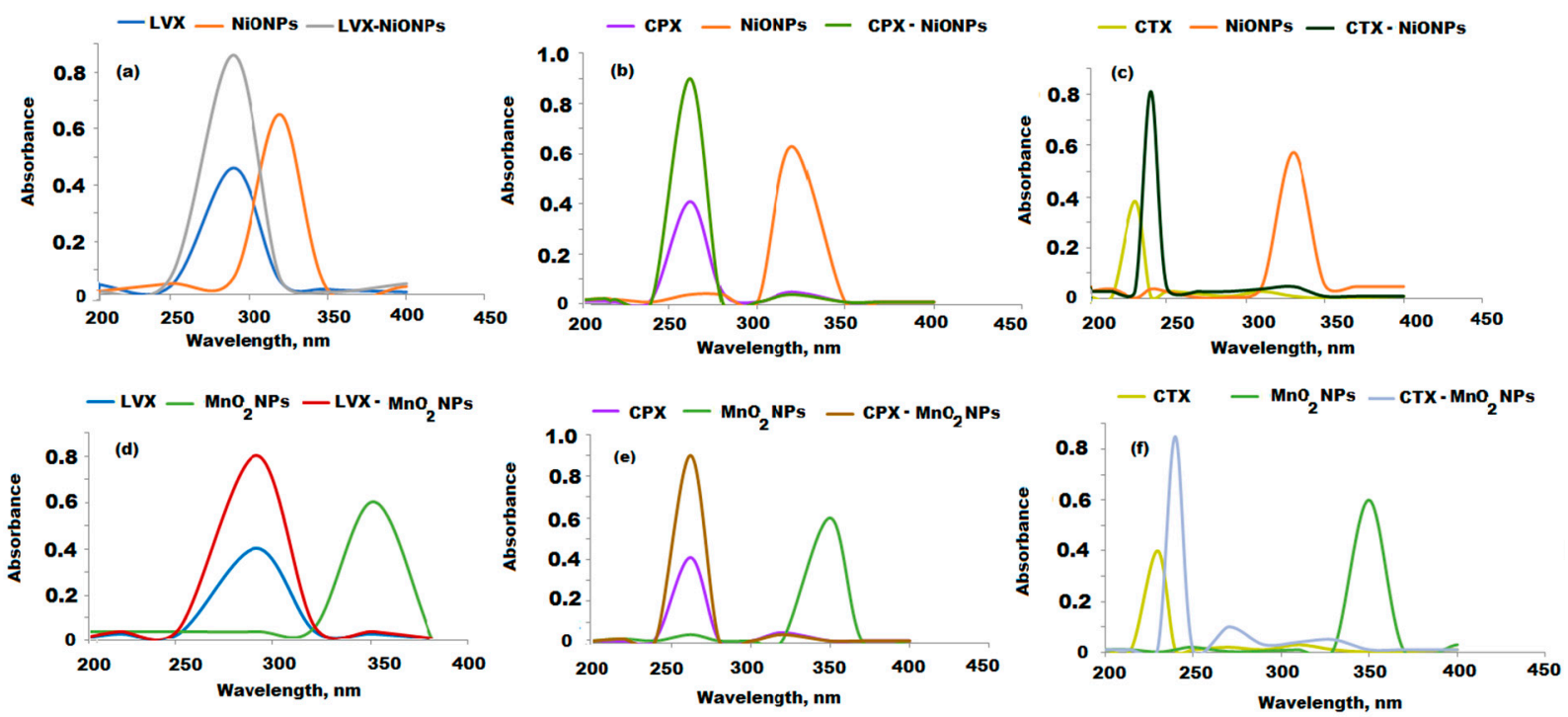

Figure 8. (a-c) The absorption spectra of $10 \mu \mathrm{g} \mathrm{mL} \mathrm{m}^{-1}$ of LVX, CPX, and CTX solutions in the presence of NiONPS and (d-f) in the presence of $\mathrm{MnO}_{2} \mathrm{NPs}$, respectively.

Table 2. Response data obtained from the determination of LVX, CPX, and CTX using the proposed spectrophotometric method in the presence of NiONPs and $\mathrm{MnO}_{2} \mathrm{NPs}$, respectively.

\begin{tabular}{|c|c|c|c|c|c|c|c|c|}
\hline Samples & $\begin{array}{l}\lambda_{\max } \\
(\mathrm{nm})\end{array}$ & $\begin{array}{l}\text { Beer's Law Limit } \\
\quad\left(\mu \mathrm{g} \mathrm{mL}^{-1}\right)\end{array}$ & $\begin{array}{l}\text { Molar Absorbitivity } \\
\text { (L. } \text { mol }^{-1} . \mathrm{cm}^{-1} \text { ) }\end{array}$ & $\begin{array}{c}\text { Sandell's Sensitivity } \\
\left(\mu \mathrm{g} / \mathrm{cm}^{2} / 0.001 \text { Absorbance Unit }\right)\end{array}$ & $\begin{array}{c}\text { Correlation } \\
\text { Coefficient, (r) }\end{array}$ & $\begin{array}{c}\text { Standard Deviation of } \\
\text { Slope }\left(S_{b}\right)\end{array}$ & $\begin{array}{l}\text { Standard Deviation of Intercept } \\
\qquad\left(S_{\mathbf{a}}\right)\end{array}$ & $\stackrel{\%}{\%} \mathrm{SE}^{*}$ \\
\hline LVX-NiONPs & 290 & $0.1-20$ & $17.9 \times 10^{3}$ & 0.0203 & 0.9986 & 0.00074 & 0.00628 & 0.15 \\
\hline CPX-NiONPs & 262 & $1.0-80$ & $11.6 \times 10^{3}$ & 0.0311 & 0.9999 & 0.00068 & 0.02809 & 0.05 \\
\hline CTX-NiONPs & 235 & $0.001-100$ & $14.5 \times 10^{3}$ & 0.0033 & 0.9995 & 0.000311 & 0.013934 & 0.04 \\
\hline LVX-MnO ${ }_{2} \mathrm{NPs}$ & 290 & $0.01-60$ & $16.8 \times 10^{3}$ & 0.0221 & 0.9974 & 0.00135 & 0.03609 & 0.08 \\
\hline $\mathrm{CPX}-\mathrm{MnO}_{2} \mathrm{NPs}$ & 262 & $0.1-160$ & $5.9 \times 10^{3}$ & 0.0610 & 0.9995 & 0.00016 & 0.01248 & 0.03 \\
\hline CTX-MnO ${ }_{2} \mathrm{NPs}$ & 235 & $0.01-80$ & $15.3 \times 10^{3}$ & 0.031 & 0.9998 & 0.00025 & 0.009233 & 0.02 \\
\hline
\end{tabular}

* SE represents the standard error.

The lower limits of detection and quantification (LOD) and (LOQ) of the investigated drugs were calculated by the equations at $3.3 \mathrm{\sigma} / \mathrm{s}$ and $10 \mathrm{\sigma} / \mathrm{s}$, respectively, where $\sigma$ represents the standard deviation of the response and $\mathrm{s}$ is the slope of the calibration graph. The recorded results showed that the LOD values were found to be $0.07,0.09$, and $0.0005 \mu \mathrm{g} \mathrm{mL}-1$ for LVX, CPX, and CTX in the presence of NiONPs and 0.002, 0.006, and $0.0007 \mu \mathrm{g} \mathrm{mL}^{-1}$ for the three mentioned drugs in the presence of $\mathrm{MnO}_{2} \mathrm{NPs}$. However, the obtained LOQ was found to be $0.21,0.27$, and $0.015 \mu \mathrm{g} \mathrm{mL} \mathrm{L}^{-1}$ for LVX, CPX, and CTX in the presence of NiONPs, while in the presence of $\mathrm{MnO}_{2} \mathrm{NPs}$, LOQ were $0.006,0.018$, and $0.0021 \mu \mathrm{g} \mathrm{mL}^{-1}$ for the same drugs, respectively.

The accuracy of the proposed spectrophotometric method was expressed as mean recoveries percentage \pm standard deviation (mean \pm SD) calculated from the obtained results. The developed methods showed good accuracy with percentage recoveries in the ranges of $99.27 \pm 1.4,99.59 \pm 0.4$, and $99.07 \pm 0.8$ for LVX, CPX, and CTX in the presence of NiONPs and $99.77 \pm 0.5,99.32 \pm 0.7$, and $99.17 \pm 0.7$ for the above-mentioned drugs, respectively (Table 3). 
Table 3. Validation data obtained from the determination of LVX, CPX, and CTX in bulk powder using the proposed spectrophotometric method in the presence of NiONPs and $\mathrm{MnO}_{2} \mathrm{NPs}$, respectively.

\begin{tabular}{|c|c|c|c|c|c|c|}
\hline Samples & $\begin{array}{c}\text { Accuracy } \\
(n=9)\end{array}$ & Intra-Day $(n=3)$ & Inter-Day $(n=3)$ & $\begin{array}{l}\text { Repeatability } \\
(\text { RSD } \%, n=6)\end{array}$ & Robustness & Ruggedness \\
\hline LVX-NiONPs & $99.27 \pm 1.4$ & $1.3 \%, 1.7 \%$ and $1.5 \%$ & $0.4 \%, 0.2 \%$ and $0.1 \%$ & 0.6 & $99.38 \pm 0.6$ & $98.56 \pm 0.8$ \\
\hline CPX-NiONPs & $99.59 \pm 0.4$ & $0.7 \%, 0.7 \%$ and $0.6 \%$ & $1.5 \%, 1.6 \%$ and $1.3 \%$ & 0.3 & $99.82 \pm 0.7$ & $98.52 \pm 0.5$ \\
\hline CTX- NiONPs & $99.07 \pm 0.8$ & $0.5 \%, 0.6 \%$ and $0.6 \%$ & $0.7 \%, 0.9 \%$ and $1.0 \%$ & 1.1 & $98.89 \pm 1.2$ & $98.76 \pm 0.7$ \\
\hline $\mathrm{LVX}-\mathrm{MnO}_{2} \mathrm{NPs}$ & $99.77 \pm 0.5$ & $0.4 \%, 0.4 \%$ and $0.6 \%$ & $1.1 \%, 1.2 \%$ and $1.4 \%$ & 0.7 & $98.94 \pm 0.8$ & $99.23 \pm 1.1$ \\
\hline $\mathrm{CPX}-\mathrm{MnO}_{2} \mathrm{NPs}$ & $99.32 \pm 0.7$ & $0.9 \%, 0.8 \%$ and $0.7 \%$ & $1.1 \%, 1.2 \%$ and $1.4 \%$ & 0.3 & $99.45 \pm 0.7$ & $98.85 \pm 0.6$ \\
\hline $\mathrm{CTX}-\mathrm{MnO}_{2} \mathrm{NPs}$ & $99.17 \pm 0.7$ & $0.6 \%, 0.6 \%$ and $0.8 \%$ & $0.9 \%, 0.8 \%$ and $1.0 \%$ & 0.8 & $99.85 \pm 0.3$ & $98.47 \pm 0.6$ \\
\hline
\end{tabular}

In order to estimate the precision of the proposed method, intra-day and inter-day assays were applied. Three different concentrations of each drug were investigated in triplicate $(n=3)$, and the recorded data were calculated as relative standard deviation percentage (RSD \%). As summarized in (Table 3 ), the calculated mean RSD \% was found to be $1.5 \%, 0.7 \%, 0.6 \%$, and $0.5 \%, 0.8 \%$, and $0.7 \%$ for intra-day assay of LVX, CPX, and $\mathrm{CTX}$ in the presence of NiONPs and $\mathrm{MnO}_{2} \mathrm{NPs}$, respectively. However, the inter-day assay displayed mean RSD $\%$ of $0.2 \%, 1.5 \%, 0.9 \%$ and $1.2 \%, 1.2 \%$, and $0.9 \%$ of the above tested drugs in the presence of NiONPs and $\mathrm{MnO}_{2} \mathrm{NPs}$, respectively. These results are less than $2 \%$, revealing the high precision of the developed method.

Under optimized experimental conditions, the selectivity of the developed spectrophotometric method for the determination of LVX, CPX, and CTX in the presence of NiONPs and $\mathrm{MnO}_{2} \mathrm{NPs}$ was studied in the presence of possible present excipients such as lactose, povidone, microcrystalline cellulose, magnesium stearate, anhydrous colloidal silica, red ferric oxide, and titanium dioxide. The tolerable values of the analytical drugs in the presence of interfering species were estimated. It was found that no significant interference was observed (Table 4). The outcomes indicated that the tolerable values of the foreign species gave a percentage error $\leq 5 \%$. Accordingly, the suggested spectrophotometric method for the determination of the three selected drugs can be considered as the selective method.

Table 4. Effect of foreign species on the determination of LVX, CPX, and CTX using the spectrophotometric method in the presence of NiONPs and $\mathrm{MnO}_{2} \mathrm{NPs}$.

\begin{tabular}{|c|c|c|c|c|c|c|}
\hline \multirow[t]{2}{*}{ Interference } & \multicolumn{2}{|c|}{$\begin{array}{c}\text { LVX } \\
\text { Tolerable Values }\end{array}$} & \multicolumn{2}{|c|}{$\begin{array}{c}\text { CPX } \\
\text { Tolerable Values }\end{array}$} & \multicolumn{2}{|c|}{$\begin{array}{c}\text { CTX } \\
\text { Tolerable Values }\end{array}$} \\
\hline & NiONPs & $\mathrm{MnO}_{2} \mathrm{NPs}$ & NiONPs & $\mathrm{MnO}_{2} \mathrm{NPs}$ & NiONPs & $\mathrm{MnO}_{2} \mathrm{NPs}$ \\
\hline Lactose & 100 & 200 & 80 & 100 & 100 & 140 \\
\hline Povidone & 400 & 420 & 200 & 200 & 250 & 300 \\
\hline Microcrystalline cellulose & 300 & 200 & 100 & 200 & 100 & 180 \\
\hline Magnesium stearate & 600 & 600 & 400 & 300 & 300 & 340 \\
\hline Anhydrous colloidal silica & 750 & 680 & 560 & 600 & 420 & 510 \\
\hline Red ferric oxide & 800 & 700 & 600 & 580 & 350 & 200 \\
\hline Titanium dioxide & 200 & 300 & 120 & 100 & 250 & 150 \\
\hline
\end{tabular}

\subsection{Analytical Application}

The developed spectrophotometric method was employed to detect LVX, CPX, and CTX in their bulk powder (Table 5). The obtained data were found to be $99.36 \pm 0.9$, $99.53 \pm 0.6$, and $98.94 \pm 0.8 \%$, for LVX, CPX, and CTX in the presence of NiONPs. Whereas, the percentage recoveries were found to be $99.70 \pm 0.7 \%, 99.64 \pm 0.6 \%$, and $99.24 \pm 0.8 \%$ for the three drugs in the presence of $\mathrm{MnO}_{2} \mathrm{NPs}$, respectively. These outcomes revealed the 
high sensitivity of the developed method in the presence of metal oxide nanoparticles due to their large surface areas and high optical features.

Table 5. Determination of LVX, CPX, and CTX in bulk powder using the proposed spectrophotometric method in the presence of NiONPs and $\mathrm{MnO}_{2} \mathrm{NPs}$.

\begin{tabular}{ccccccccc}
\hline \multicolumn{1}{c}{ Samples } & $\begin{array}{c}\text { Taken } \\
\text { Conc. Range } \\
\left(\mu \mathbf{~ m L}^{-1}\right)\end{array}$ & $\begin{array}{c}\text { Found Range } \\
\left(\mu \mathbf{~ m L}^{-1}\right)\end{array}$ & \% Recovery & Mean \pm SD & $n$ & Variance & \%SE & \% RSD \\
\hline LVX-NiONPs & $0.1-20$ & $0.1-19.66$ & $97.9-100.66$ & $99.36 \pm 0.9$ & 7 & 0.81 & 0.34 & 0.91 \\
\hline $\mathrm{CPX}-\mathrm{NiONPs}$ & $1.0-80$ & $1.0-79.25$ & $99.0-100.5$ & $99.53 \pm 0.6$ & 7 & 0.36 & 0.23 & 0.60 \\
\hline $\mathrm{CTX}-\mathrm{NiONPs}$ & $1.0-80$ & $0.995-97.31$ & $97.8-100.1$ & $98.94 \pm 0.8$ & 7 & 0.64 & 0.30 & 0.81 \\
\hline $\mathrm{LVX}-\mathrm{MnO}_{2} \mathrm{NPs}$ & $0.1-60$ & $0.099-59.85$ & $99.0-100.5$ & $99.70 \pm 0.7$ & 7 & 0.49 & 0.26 & 0.70 \\
\hline $\mathrm{CPX}-\mathrm{MnO}_{2} \mathrm{NPs}$ & $1.0-160$ & $1.0-158.22$ & $98.9-100.5$ & $99.64 \pm 0.6$ & 7 & 0.36 & 0.23 & 0.60 \\
\hline $\mathrm{CTX}-\mathrm{MnO}_{2} \mathrm{NPs}$ & $1.0-80$ & $0.991-97.02$ & $98.0-100.3$ & $99.24 \pm 0.8$ & 7 & 0.64 & 0.30 & 0.81 \\
\hline
\end{tabular}

The developed analytical method was applied to quantify the investigated drugs in their commercial dosage forms (Tavanic ${ }^{\circledR} 500 \mathrm{mg}$ LVX/tablet; Keflex ${ }^{\circledR} 500 \mathrm{mg}$ CPX/tablet; and Foxime ${ }^{\circledR} 1 \mathrm{~g} \mathrm{CTX/vial),} \mathrm{and} \mathrm{the} \mathrm{results} \mathrm{were} \mathrm{summarized} \mathrm{in} \mathrm{Table} \mathrm{6.} \mathrm{The} \mathrm{recorded}$ results were found to be $99.64 \pm 0.6 \%, 99.60 \pm 0.4 \%$, and $99.33 \pm 0.7 \%$ for LVX, CPX, and CTX in the presence of NiONPs. Whereas, the percentage recoveries were found to be $99.48 \pm 0.4 \%, 99.67 \pm 0.6 \%$, and $99.18 \pm 0.8 \%$ for the three drugs in the presence of $\mathrm{MnO}_{2} \mathrm{NPs}$, respectively. All results were statistically assessed using Student's $t$-test and variance ratio F-test [68] and compared with those obtained from previously reported methods [69-71]. It was observed that the high sensitivity of the proposed spectrophotometric method for the determination of LVX, CPX, and CTX in the presence of NiONPs and $\mathrm{MnO}_{2} \mathrm{NPs}$ can be attributed to the catalytic properties of these nanoparticles. Metal oxide nanoparticles enhance the localized surface plasmon resonances and collective oscillations of conduction electrons that strongly couple to light at particular wavelengths and produce their extremely high optical properties.

Table 6. Determination of LVX, CPX, and CTX in their commercial dosage forms using spectrophotometry in the presence of $\mathrm{NiONPs}$ and $\mathrm{MnO}_{2} \mathrm{NPs}$, respectively.

\begin{tabular}{|c|c|c|c|c|c|c|c|c|c|c|c|}
\hline Samples & $\begin{array}{c}\text { Taken } \\
\left(\mu \mathrm{g} \mathrm{mL}^{-1}\right)\end{array}$ & $\begin{array}{c}\text { Found } \\
\left(\mu \mathrm{g} \mathrm{mL} L^{-1}\right)\end{array}$ & $\begin{array}{c}\% \\
\text { Recovery }\end{array}$ & Mean \pm SD & $n$ & Variance & $\begin{array}{l}\% \\
\text { SE }\end{array}$ & $\begin{array}{c}\% \\
\text { RSD }\end{array}$ & $\begin{array}{c}\text { Reference } \\
\text { Method } \\
\text { [69-71] }\end{array}$ & $\begin{array}{c}t \text {-Test } \\
(2.228)^{*}\end{array}$ & $\begin{array}{l}F \text {-Test } \\
(5.05)^{*}\end{array}$ \\
\hline LVX-NiONPs & $2.0-20$ & $1.98-19.95$ & 99.0-100.5 & $99.64 \pm 0.6$ & 6 & 0.32 & 0.23 & 0.57 & \multirow{2}{*}{$99.43 \pm 0.9$} & 0.482 & 2.53 \\
\hline $\mathrm{LVX}-\mathrm{MnO}_{2} \mathrm{NPs}$ & $1.0-60$ & $0.99-59.6$ & $99.0-100.0$ & $99.60 \pm 0.4$ & 6 & 0.16 & 0.16 & 0.40 & & 0.682 & 4.00 \\
\hline CPX-NiONPs & $5.0-80$ & $5.0-79.8$ & $98.0-100.0$ & $99.33 \pm 0.7$ & 6 & 0.49 & 0.29 & 0.70 & \multirow{2}{*}{$99.28 \pm 0.6$} & 0.341 & 1.31 \\
\hline $\mathrm{CPX}-\mathrm{MnO}_{2} \mathrm{NPs}$ & $10-160$ & $9.98-158.5$ & $98.8-100.0$ & $99.48 \pm 0.4$ & 6 & 0.16 & 0.16 & 0.40 & & 0.693 & 2.25 \\
\hline CTX-NiONP & $5.0-80$ & $4.96-79.34$ & $99.2-100.6$ & $99.67 \pm 0.6$ & 6 & 0.36 & 0.24 & 0.60 & \multirow{2}{*}{$99.03 \pm 0.7$} & 1.724 & 1.00 \\
\hline $\mathrm{CTX}-\mathrm{MnO}_{2} \mathrm{NPs}$ & $5.0-80$ & $5.02-79.21$ & $97.8-100.4$ & $99.18 \pm 0.8$ & 6 & 0.64 & 0.33 & 0.81 & & 0.341 & 1.306 \\
\hline
\end{tabular}

The high optical activity of these metal oxide nanoparticles was also due to their large surface area with tunable properties generating during their nanoscale synthesis and their ability to absorb the oxygen and sulfur groups of the analyzed drugs and enhance their spectrophotometric determination.

Furthermore, a comparative study was carried out between the results obtained from the suggested spectrophotometric method and the previously reported analytical techniques including spectrophotometric, electrochemical, and chromatographic methods. The outcomes have been summarized in Table 7. Practically, the suggested spectrophotometric methods using metal oxide nanoparticles displayed high sensitivity, cost benefits, and easy 
production, and the echo-friendly method depends on the preparation of nanoparticles using natural sources. Moreover, it is more accurate and precise and does not required higher technical skills when compared to other chromatographic or electrochemical techniques.

Table 7. A comparative study between the results obtained from the determination of LVX, CPX, and CTX using spectrophotometry in the presence of NiONPs and $\mathrm{MnO}_{2} \mathrm{NPs}$, respectively and the previously reported analytical techniques.

\begin{tabular}{|c|c|c|c|c|}
\hline Analytical Techniques & Reagent & $\begin{array}{l}\text { Linear conc. Range } \\
\mu \mathrm{g} \mathrm{mL^{-1 }}\end{array}$ & LOD & Reference \\
\hline \multirow{3}{*}{ Spectrophotometry } & LVX, Methanolic solution of perchloric acid & $2.5-20$ & $0.8 \mu \mathrm{g} \mathrm{mL}^{-1}$ & {$[6]$} \\
\hline & $\begin{array}{l}\text { CPX, Oxidation using excess amount of } \\
\text { N-bromosuccinimide }\end{array}$ & $1.0-9.0$ & $0.023 \mu \mathrm{g} \mathrm{mL}^{-1}$ & [7] \\
\hline & CTX, Metal Cu (II) complex & $20-140$ & - & {$[8]$} \\
\hline \multirow{2}{*}{ Fluorescence } & $\begin{array}{l}\text { LVX, Electron transfer mechanism quenched the } \\
\text { fluorescence of GSH-CdTe QDs }\end{array}$ & $0.73-7.30$ & $1.53 \mathrm{ng} \mathrm{mL}^{-1}$ & [9] \\
\hline & $\begin{array}{l}\text { CTX, Bromate-bromide and, acriflavine as } \\
\text { fluorescent dye }\end{array}$ & $0.1-3.0$ & 0.013 & {$[10]$} \\
\hline \multirow[t]{3}{*}{ Electrochemical } & $\begin{array}{l}\text { LVX, Nanocomposite of silver nanoparticles on a } \\
\text { thin and porous nickel oxide film. }\end{array}$ & $0.25-100 \mu \mathrm{M}$ & - & {$[12]$} \\
\hline & CPX, Disposable graphite electrode & $0.5-4.0 \mathrm{mM}$ & $0.12 \mu \mathrm{M}$ & {$[13]$} \\
\hline & $\begin{array}{l}\text { CTX, A multi-walled carbon nanotubes (MWNT) } \\
\text { coated glassy carbon electrode }\end{array}$ & $0.004-10.0 \mu \mathrm{M}$ & $1.0 \mathrm{nM}$ & {$[14]$} \\
\hline \multirow[t]{3}{*}{ Chromatography } & $\begin{array}{l}\text { LVX, Acetonitrile and } 0.01 \mathrm{M} \text { potassium } \\
\text { dihydrogen aqueous solution }(\mathrm{pH} 3.4 ; 14: 86 v / v)\end{array}$ & $0.1-12$ & 0.05 & {$[15]$} \\
\hline & CPX, OPA: Acetonitrile $(30: 70 v / v)$ & $100-500$ & 0.357 & [16] \\
\hline & CTX, Methanol:Phosphate buffer (1000:130 v/v) & $0.5-1.5$ & $35.5 \mathrm{ng} \mathrm{mL}^{-1}$ & [17] \\
\hline \multirow{3}{*}{ Proposed method } & \multirow{3}{*}{$\begin{array}{l}\text { Spectrophotometric measurement in the presence } \\
\text { of NiONPs and } \mathrm{MnO}_{2} \mathrm{NPs}\end{array}$} & $0.1-20$ & 0.07 & LVX \\
\hline & & $1.0-80$ & 0.09 & CPX \\
\hline & & $0.001-100$ & 0.0005 & CTX \\
\hline
\end{tabular}

\section{Conclusions}

The present study suggested a sensitive and selective spectrophotometric method for the detection of antibiotics (LVX, CPX, and CTX) in their pharmaceutical formulations. The detection is based on the enhancement effect of NiONPs and $\mathrm{MnO}_{2} \mathrm{NPs}$ on absorbance signals. The outcome of the investigation revealed that the increase in absorbance signals is proportional to the selected drug concentrations. The suggested method exhibits linear behavior over concentration ranges of $0.1-20,1-80$, and $0.001-100 \mu \mathrm{g} \mathrm{mL}$ with least regression equations of $Y=0.0492 C+0.0334(r=0.9986), Y=0.0319 C+0.0699$ $(r=0.9999)$, and $Y=0.0304 C+0.0312(r=0.9995)$ for LVX, CPX, and CTX in the presence of NiONPs and $Y=0.0464 C+0.0956(r=0.9974), Y=0.0163 C+0.0489(r=0.9995)$, and $\mathrm{Y}=0.0321 \mathrm{C}+0.0835(\mathrm{r}=0.9998)$ for the above-mentioned drugs in the presence of $\mathrm{MnO}_{2} \mathrm{NPs}$. The suggested spectrophotometric methods were successfully applied to determine the studied drugs in their pharmaceutical preparations. The recorded results were found to be $99.64 \pm 0.6 \%, 99.60 \pm 0.4 \%$, and $99.33 \pm 0.7 \%$, for LVX, CPX, and $\mathrm{CTX}$ in the presence of NiONPs. Whereas, the percentage recoveries were found to be $99.48 \pm 0.4 \%, 99.67 \pm 0.6 \%$, and $99.18 \pm 0.8 \%$ for the three drugs in the presence of $\mathrm{MnO}_{2} \mathrm{NPs}$, respectively. The high sensitivity of the proposed spectrophotometric method for the determination of LVX, CPX, and CTX in the presence of NiONPs and $\mathrm{MnO}_{2} \mathrm{NPs}$ can be attributed to the catalytic properties of these nanoparticles. Metal oxide nanoparticles enhance localized surface plasmon resonances and the collective oscillations of conduction electrons that strongly couple to light at particular wavelengths and produce their extremely high optical properties. 
Author Contributions: Conceptualization, funding acquisition, and project administration, N.A.A.; visualization, W.A.A.-O.; supervision, A.M.A.-M.; investigation, formal analysis, and data curation, H.A.A.; Writing—original draft preparation, writing—review and editing, M.F.E.-T. All authors have read and approved to the published version of manuscript.

Funding: Researchers Supporting Project number (RSP-2020/272), King Saud University, Riyadh, Saudi Arabia.

Data Availability Statement: All data of this study are included within the text.

Acknowledgments: This study was supported by Researchers Supporting Project number (RSP2020/272), King Saud University, Riyadh, Saudi Arabia.

Conflicts of Interest: The authors declare no conflict of interest.

\section{References}

1. Morse, S.S. Factors in the emergence of infectious diseases. In Plagues and Politics; Price-Smith, A.T., Ed.; Global Issues Series; Palgrave Macmillan: London, UK, 2001; pp. 8-26. [CrossRef]

2. Etebu, E.; Arikekpar, I. Antibiotics: Classification and mechanisms of action with emphasis on molecular perspectives. Int. J. Appl. Microbiol. Biotechnol. Res. 2016, 4, 90-101.

3. Sharma, P.C.; Jain, A.; Jain, S. Fluoroquinolone antibacterial: A review on chemistry, microbiology and therapeutic prospects. Acta Pol. Pharm. 2009, 66, 587-604. [PubMed]

4. Shahbaz, K. Cephalosporins: Pharmacology and chemistry. Pharm. Biol. Eval. 2017, 4, 234-238. [CrossRef]

5. LeFrock, J.L.; Prince, R.A.; Left, R.D. Mechanism of action, antimicrobial activity, pharmacology, adverse effects, and clinical efficacy of cefotaxime. Pharmacother. J. Human Pharmacol. Drug Therap. 1982, 2, 174-184. [CrossRef]

6. El-Yazbi, A.F.; Khamis, E.F.; Youssef, R.M.; El-Sayed, M.A.; Aboukhalil, F.M. Green analytical methods for simultaneous determination of compounds having relatively disparate absorbance; application to antibiotic formulation of azithromycin and levofloxacin. Heliyon 2020, 6, e04819. [CrossRef]

7. Al-Talibi, E.S. Indirect spectrophotometric determination of cefalexin monohydrate, ceftriaxone sodium and cefotaxim sodium in pharmaceuticals using N-bromosuccinimde and evans blue dye. J. Educ. Sci. 2020, 29, 11-31.

8. Kondaiah, S.; Chowdary, P.G.; Reddy, G.N.R.; Rao, V.S. Spectrophotometric determination studies of cefotaxime (CFX) and their CFX-Cd (II) and CFX-Cu (II) complexes. Orient. J. Chem. 2017, 33, 258-268. [CrossRef]

9. Tan, X.; Li, Q.; Yang, J. A simple fluorescence method detection levofloxacin in milk based on GSH-CdTe QDs. J. Mol. Struct. 2020, 1201, 127175. [CrossRef]

10. Saeed, A.M.; Salih, E.S. Indirect spectrofluorometric method for the determination of cefotaxime sodium, ciprofloxacin hydrochloride and famotidine in pharmaceuticals using bromate-bromide and acriflavine dye. Baghdad Sci. J. 2020, 17, 1-15.

11. Stirbet, D.; Vasilescu, I.; Radu, G.L. Spectrofluorimetric analysis of cefotaxime sodium by using 4-fluoro-7-nitrobenzofurazan as derivatization agent. UPB Sci. Bul. Ser. B Chem. Mat. Sci. 2014, 76, 89-98.

12. Liu, C.; Xie, D.; Liu, P.; Xie, S.; Wang, S.; Cheng, F.; Zhang, M.; Wang, L. Voltammetric determination of levofloxacin using silver nanoparticles deposited on a thin nickel oxide porous film. Microchim. Acta 2019, 186, 1-10. [CrossRef]

13. Ozkorucuklu, S.P.; Uka, B.; Baştemur, G.Y. Voltammetric analysis of cephalexin and cefazoline in pharmaceutical formulation and biological samples. J. Turk. Chem. Soc. 2019, 6, 217-224.

14. Shahrokhian, S.; Rastgar, S. Construction of an electrochemical sensor based on the electrodeposition of Au-Pt nanoparticles mixtures on multi-walled carbon nanotubes film for voltammetric determination of cefotaxime. Analyst 2012, 137, 2706-2715. [CrossRef]

15. Aguilar-Carrasco, J.C.; Hernandez-Pineda, J.; Jimenez-Andrade, J.M.; Flores-Murrieta, F.J.; Carrasco-Portugal, M.D.C.; LopezCanales, J.S. Rapid and sensitive determination of levofloxacin in microsamples of human plasma by high-performance liquid chromatography and its application in a pharmacokinetic study. Biomed. Chromatogr. 2015, 29, 341-345. [CrossRef]

16. Rao, A.L.; Prasanthi, T.; Spandana, U.S. Stability indicating RP-HPLC method development and validation for the analysis of cephalexin and bromhexine in pharmaceutical dosage form. Int. J. Res. Ayush Pharm. Sci. 2017, 1, 137-147.

17. Al-Hakkani, M.F. HPLC analytical method validation for determination of cefotaxime in the bulk and finished pharmaceutical dosage form. Sust. Chem. Eng. 2020, 1, 33-42.

18. Agberien, A.V.; Ormeci, B. Monitoring of cyanobacteria in water using spectrophotometry and first derivative of absorbance. Water 2020, 12, 124. [CrossRef]

19. Duman, S.; Erbas, Z.; Soylak, M. Ultrasound-assisted magnetic solid phase microextraction of patent blue V on magnetic multiwalled carbon nanotubes prior to its spectrophotometric determination. Microchem. J. 2020, 159, 105468. [CrossRef]

20. Hulla, J.E.; Sahu, S.C.; Hayes, A.W. Nanotechnology: History and future. Human Exp. Toxicol. 2015, 34, 1318-1321. [CrossRef]

21. Khan, I.; Saeed, K.; Khan, I. Nanoparticles: Properties, applications and toxicities. Arab. J. Chem. 2019, 12, 908-931. [CrossRef]

22. Mudshinge, S.R.; Deore, A.B.; Patil, S.; Bhalgat, C.M. Nanoparticles: Emerging carriers for drug delivery. Saudi Pharm. J. 2011, 19, 129-141. [CrossRef] 
23. Chavali, M.S.; Nikolova, M.P. Metal oxide nanoparticles and their applications in nanotechnology. SN Appl. Sci. 2019, 1, 607. [CrossRef]

24. Amin, S.; Tahira, A.; Solangi, A.; Mazzaro, R.; Ibupoto, Z.H.; Vomiero, A. A sensitive enzyme-free lactic acid sensor based on NiO nanoparticles for practical applications. Anal. Methods 2019, 11, 3578-3583. [CrossRef]

25. Liu, Z.; Zhu, A.; Cai, F.; Tao, L.; Zhou, Y.; Zhao, Z.; Zhou, H. Nickel oxide nanoparticles for efficient hole transport in pin and nip perovskite solar cells. J. Mater. Chem. A 2017, 5, 6597-6605. [CrossRef]

26. Gajengi, A.L.; Sasaki, T.; Bhanage, B.M. NiO nanoparticles catalyzed three component coupling reaction of aldehyde, amine and terminal alkynes. Catal. Commun. 2015, 72, 174-179. [CrossRef]

27. Qian, G.; Zhang, Y.; Li, L.; Zhang, R.; Xu, J.; Cheng, Z.; Shen, Y. Single-crystal nickel-rich layered-oxide battery cathode materials: Synthesis, electrochemistry, and intra-granular fracture. Energy Stor. Mater. 2020, 27, 140-149. [CrossRef]

28. Bano, S.; Nazir, S.; Munir, S.; AlAjmi, M.F.; Afzal, M.; Mazhar, K. Smart nickel oxide based core-shell nanoparticles for combined chemo and photodynamic cancer therapy. Int. J. Nanomed. 2016, 11, 3159.

29. Karthik, K.; Radhika, D.; Sadasivuni, K.K.; Reddy, K.R. Nanostructured metal oxides and its hybrids for biomedical applications. Adv. Colloid. Interface Sci. 2020, 281, 102178.

30. Chen, M.; Pan, Z.; Jin, X.; Chen, Z.; Zhong, Y.; Wang, X.; Zhang, Y. A highly integrated All-manganese battery with oxide nanoparticles supported on the cathode and anode by super-aligned carbon nanotubes. J. Mater. Chem. A 2019, 7, 4494-4504. [CrossRef]

31. Fei, J.; Sun, L.; Zhou, C.; Ling, H.; Yan, F.; Zhong, X.; Liu, Z. Tuning the synthesis of manganese oxides nanoparticles for efficient oxidation of benzyl alcohol. Nanoscale Res. Lett. 2017, 12, 23. [CrossRef]

32. Chen, H.; Chu, P.K.; He, J.; Hu, T.; Yang, M. Porous magnetic manganese oxide nanostructures: Synthesis and their application in water treatment. J. Colloid. Interface Sci. 2011, 359, 68-74. [CrossRef]

33. Ding, B.; Zheng, P.; Ma, P.A.; Lin, J. Manganese oxide nanomaterials: Synthesis, properties, and theranostic applications. Adv. Mater. 2020, 32, 1905823. [CrossRef]

34. Ahn, M.S.; Ahmad, R.; Yoo, J.Y.; Hahn, Y.B. Synthesis of manganese oxide nanorods and its application for potassium ion sensing in water. J. Colloid Interface Sci. 2018, 516, 364-370. [CrossRef]

35. Ahamed, A.J.; Kumar, P.V.; Karthikeyan, M. Wet chemical synthesis and characterization of NiO nanoparticles. Int. J. Nano. Corros. Sci. Eng. 2015, 2, 31-38.

36. Ghosh, D.; Bhandari, S.; Khastgir, D. Synthesis of $\mathrm{MnO}_{2}$ nanoparticles and their effective utilization as UV protectors for outdoor high voltage polymeric insulators used in power transmission lines. Phys. Chem. Chem. Phys. 2016, 18, 32876-32890. [CrossRef]

37. Teoh, L.G.; Li, K.D. Synthesis and characterization of $\mathrm{NiO}$ nanoparticles by sol-gel method. Mater. Trans. 2012, 53, 2135-2140. [CrossRef]

38. Tang, W.; Shan, X.; Li, S.; Liu, H.; Wu, X.; Chen, Y. Sol-gel process for the synthesis of ultrafine $\mathrm{MnO}_{2}$ nanowires and nanorods. Mater. Letter. 2014, 132, 317-321. [CrossRef]

39. Farhadi, S.; Roostaei-Zaniyani, Z. Preparation and characterization of NiO nanoparticles from thermal decomposition of the [Ni $(\mathrm{en})_{3}$ ] $\left(\mathrm{NO}_{3}\right)_{2}$ complex: A facile and low-temperature route. Polyhedron 2011, 30, 971-975. [CrossRef]

40. Zhu, L.; Lv, J.; Yu, X.; Zhao, H.; Sun, C.; Zhou, Z.; Ying, Y.; Tan, L. Further construction of $\mathrm{MnO}_{2}$ composite through in-situ growth on MXene surface modified by carbon coating with outstanding catalytic properties on thermal decomposition of ammonium perchlorate. Appl. Surf. Sci. 2020, 502, 144171. [CrossRef]

41. Singh, J.; Dutta, T.; Kim, K.H.; Rawat, M.; Samddar, P.; Kumar, P. Green synthesis of metals and their oxide nanoparticles: Applications for environmental remediation. J. Nanobiotechnol. 2018, 16, 1-24. [CrossRef]

42. Armenta, S.; Garrigues, S.; De la Guardia, M. Green analytical chemistry. TrAC Trend. Anal. Chem. 2008, 27, 497-511. [CrossRef]

43. Ortega, F.; Arce, V.B.; Garcia, M.A. Nanocomposite starch-based films containing silver nanoparticles synthesized with lemon juice as reducing and stabilizing agent. Carbohydr. Polym. 2021, 252, 117208. [CrossRef]

44. Krishna, P.G.; Ananthaswamy, P.P.; Trivedi, P.; Chaturvedi, V.; Mutta, N.B.; Sannaiah, A.; Erra, A.; Yadavalli, T. Antitubercular activity of $\mathrm{ZnO}$ nanoparticles prepared by solution combustion synthesis using lemon juice as bio-fuel. Mater. Sci. Eng. C 2017, 75, 1026-1033. [CrossRef] [PubMed]

45. Annu, A.A.; Ahmed, S. Green synthesis of metal, metal oxide nanoparticles, and their various applications. In Handbook of Ecomaterials; Springer: Berlin/Heidelberg, Germany, 2018; pp. 1-45.

46. Jeevanandam, J.; Chan, Y.S.; Danquah, M.K. Biosynthesis of metal and metal oxide nanoparticles. Chem. Bio. Eng. Rev. 2016, 3, 55-67. [CrossRef]

47. Manoj, D.; Saravanan, R.; Santhanalakshmi, J.; Agarwal, S.; Gupta, V.K.; Boukherroub, R. Towards green synthesis of monodisperse $\mathrm{Cu}$ nanoparticles: An efficient and high sensitive electrochemical nitrite sensor. Sensor. Actuat. B 2018, 266, 873-882. [CrossRef]

48. Kumar, V.; Singh, K.; Panwar, S.; Mehta, S.K. Green synthesis of manganese oxide nanoparticles for the electrochemical sensing of p-nitrophenol. Int. Nano Lett. 2017, 7, 123-131. [CrossRef]

49. Hoseinpour, V.; Souri, M.; Ghaemi, N. Green synthesis, characterisation, and photocatalytic activity of manganese dioxide nanoparticles. Micro. Nano Lett. 2018, 13, 1560-1563. [CrossRef]

50. Ezhilarasi, A.A.; Vijaya, J.J.; Kaviyarasu, K.; Kennedy, L.J.; Ramalingam, R.J.; Al-Lohedan, H.A. Green synthesis of NiO nanoparticles using Aegle marmelos leaf extract for the evaluation of in-vitro cytotoxicity, antibacterial and photocatalytic properties. J. Photochem. Photobiol. B Biol. 2018, 180, 39-50. [CrossRef] [PubMed] 
51. Beitollai, H.; Nejad, F.G.; Tajik, S.; Jahani, S.; Biparva, P. Voltammetric determination of amitriptyline based on graphite screen printed electrode modified with a Copper Oxide nanoparticles. Int. J. Nano Dimens. 2017, 8, 197-205.

52. Zheng, Y.; Huang, Y.; Shi, H.; Fu, L. Green biosynthesis of ZnO nanoparticles by plectranthus amboinicus leaf extract and their application for electrochemical determination of norfloxacin. Inorg. Nano Met. Chem. 2019, 49, 277-282. [CrossRef]

53. Kuppusamy, P.; Yusoff, M.M.; Maniam, G.P.; Govindan, N. Biosynthesis of metallic nanoparticles using plant derivatives and their new avenues in pharmacological applications-An updated report. Saudi Pharm. J. 2016, 24, 473-484. [CrossRef] [PubMed]

54. Dharmaraj, N.; Prabu, P.; Nagarajan, S.; Kim, C.H.; Park, J.H.; Kim, H.Y. Synthesis of nickel oxide nanoparticles using nickel acetate and poly (vinyl acetate) precursor. Mater. Sci. Eng. 2006, 128, 111-114. [CrossRef]

55. Dessie, Y.; Tadesse, S.; Eswaramoorthy, R. Physicochemical parameter influences and their optimization on the biosynthesis of $\mathrm{MnO}_{2}$ nanoparticles using Vernonia amygdalina leaf extract. Arab. J. Chem. 2020, 13, 6472-6492. [CrossRef]

56. Goyal, M.; Singh, M. Size and shape dependence of optical properties of nanostructures. Appl. Phys. A 2020, 126, 1-8. [CrossRef]

57. Sabouri, Z.; Akbari, A.; Hosseini, H.A.; Darroudi, M. Facile green synthesis of NiO nanoparticles and investigation of dye degradation and cytotoxicity effects. J. Mol. Struct. 2018, 1173, 931-936. [CrossRef]

58. Kumar, A.S.R.; Kishore, N.; Budhiraja, N. Preparation and characterization of NiO nanoparticles by Co-Precipitation method. Int. J. Eng. Appl. Manag. Sci. Paradig. 2013, 6, 64-67.

59. Mahmoud, A.M.; Ibrahim, F.A.; Shaban, S.A.; Youssef, N.A. Adsorption of heavy metal ion from aqueous solution by nickel oxide nano catalyst prepared by different methods. Egypt. J. Pet. 2015, 24, 27-35. [CrossRef]

60. El-kemary, M.; Nagy, N.; El-Mehasseb, I. Nickel oxide nanoparticles, Synthesis and spectral studies of interactions with glucose. Mat. Sci. Semcond. Proc. 2013, 16, 1747-1752. [CrossRef]

61. Jaganyi, D.; Altaf, M.; Wekesa, I. Synthesis and characterization of whisker-shaped $\mathrm{MnO}_{2}$ nanostructure at room temperature. Appl. Nanosci. 2013, 3, 329-333. [CrossRef]

62. Prasad, K.S.; Patra, A. Green synthesis of $\mathrm{MnO}_{2}$ nanorods using Phyllanthus amarus plant extract and their fluorescence studies. Green Process. Synth. 2017, 6, 549-554. [CrossRef]

63. Qiao, H.; Wei, Z.; Yang, H.; Zhu, L.; Yan, X. Preparation and characterization of NiO nanoparticles by anodic arc plasma method. J. Nanomater. 2009, 2009, 1-5. [CrossRef]

64. Shaker, K.S.; AbdAlsalm, A.H. Synthesis and characterization nano structure of $\mathrm{MnO}_{2}$ via chemical method. Eng. Technol. J. 2018, 36, 946-950. [CrossRef]

65. Iqbal, J.; Abbasi, B.A.; Mahmood, T.; Hameed, S.; Munir, A.; Kanwal, S. Green synthesis and characterizations of Nickel oxide nanoparticles using leaf extract of Rhamnus virgata and their potential biological applications. Appl. Organomet. Chem. 2019, 33, e4950. [CrossRef]

66. Liu, X.M.; Fu, S.Y.; Huang, C.J. Synthesis, characterization and magnetic properties of $\beta-\mathrm{MnO}_{2}$ nanorods. Powder Technol. 2005, 154, 120-124. [CrossRef]

67. ICH-Q2 (R1) Validation and Analytical Procedures: Text and Methodology. In Proceedings of the International Conference on Harmonization guidelines, Geneva, Switzerland, 8-15 November 2005.

68. Miller, J.C.; Miller, J.N. Statistics for Analytical Chemistry, 3rd ed.; Ellis Horwood PTR Prentice Hall: New York, NY, USA, 1993.

69. Desai, V.N.; Afieroho, O.E.; Dagunduro, B.O.; Okonkwo, T.J.; Ndu, C.C. A simple UV spectrophotometric method for the determination of levofloxacin in dosage formulations. Trop. J. Pharm. Res. 2011, 10, 75-79. [CrossRef]

70. Khan, M.N.; Ahmad, J.; Jan, M.N.; Gulab, H.; Idrees, M. Development and validation of a new spectrophotometric method for the determination of cephalexin monohydrate in pure form and pharmaceutical formulations. J. Braz. Chem. Soc. 2016, 27, 912-918. [CrossRef]

71. Bushra, M.U.; Akter, N.; Hassan, M.R.; Islam, A.; Hossain, M.R. Development and validation of a simple UV spectrophotometric method for the determination of cefotaxime sodium in bulk and pharmaceutical formulation. IOSR J. Pharm. 2014, 4, 74-77. 